\title{
Gaining Legitimacy by Being Different: Optimal Distinctiveness in Crowdfunding Platforms
}

DOI:

10.5465/amj.2018.0620

\section{Document Version}

Accepted author manuscript

Link to publication record in Manchester Research Explorer

\section{Citation for published version (APA):}

Taeuscher, K., Bouncken, R. B., \& Pesch, R. (2020). Gaining Legitimacy by Being Different: Optimal Distinctiveness in Crowdfunding Platforms. Academy of Management Journal, 64(1), 149-179. https://doi.org/10.5465/amj.2018.0620

\section{Published in:}

Academy of Management Journal

\section{Citing this paper}

Please note that where the full-text provided on Manchester Research Explorer is the Author Accepted Manuscript or Proof version this may differ from the final Published version. If citing, it is advised that you check and use the publisher's definitive version.

\section{General rights}

Copyright and moral rights for the publications made accessible in the Research Explorer are retained by the authors and/or other copyright owners and it is a condition of accessing publications that users recognise and abide by the legal requirements associated with these rights.

\section{Takedown policy}

If you believe that this document breaches copyright please refer to the University of Manchester's Takedown Procedures [http://man.ac.uk/04Y6Bo] or contact uml.scholarlycommunications@manchester.ac.uk providing relevant details, so we can investigate your claim.

\section{OPEN ACCESS}




\title{
Gaining Legitimacy by Being Different:
}

\section{Optimal Distinctiveness in Crowdfunding Platforms}

\author{
Karl Taeuscher \\ Alliance Manchester Business School \\ University of Manchester \\ Karl.Taeuscher@manchester.ac.uk \\ Ricarda Bouncken \\ University of Bayreuth \\ Bouncken@uni-bayreuth.de \\ Robin Pesch \\ Newcastle University Business School \\ Robin.Pesch@ newcastle.ac.uk
}

Acknowledgments: We are very grateful to Zeki Simsek and three anonymous reviewers for their support and many insightful suggestions that have substantively improved our article throughout the review process. We also thank Jeff Covin, Mark Healey, Joseph Lampel, and Silvia Massini for their insights and helpful comments on earlier drafts of this article.

Correspondence concerning this article should be addressed to Karl Taeuscher (Karl.Taeuscher@manchester.ac.uk), Manchester Institute of Innovation Research, Alliance Manchester Business School, University of Manchester, Booth St W, Manchester M15 6PB, United Kindgom. 


\title{
Gaining Legitimacy by Being Different:
}

\section{Optimal Distinctiveness in Crowdfunding Platforms}

\begin{abstract}
How do new ventures gain legitimacy and attract critical resources? An increasing body of cultural entrepreneurship research highlights an "optimal distinctiveness" trade-off: new ventures need to be distinctive from their peers to stand out, yet distinctiveness counteracts the attainment of organizational legitimacy. In this paper, we challenge the underlying assumption that distinctiveness necessarily counteracts the attainment of legitimacy and propose that distinctiveness can become a source of legitimacy. This proposition matters because it fundamentally alters the relationship between distinctiveness and resource acquisition from certain audiences. We build on these theoretical arguments to examine new ventures' resource acquisition from crowdfunders, one of the most important audiences for new ventures. Analysis of 28,425 crowdfunding campaigns across 39 market categories strongly supports our arguments, showing that higher levels of distinctiveness lead to superior crowdfunding performance. We further demonstrate that the legitimating effect of distinctiveness intensifies under the absence of alternative sources of legitimacy. Our study contributes by uncovering a new mechanism and three contingencies for the "optimal distinctiveness" trade-off.
\end{abstract}

New ventures need to gain legitimacy from resource-providing audiences to acquire critical resources (Aldrich \& Fiol, 1994; Lounsbury \& Glynn, 2001; Zimmerman \& Zeitz, 2002). The attainment of legitimacy - "a generalized perception or assumption that the actions of an entity are desirable, proper, or appropriate within some socially constructed system of norms, values, beliefs, and definitions" (Suchman, 1995: 574) ${ }^{1}$ - is important for all organizations but particularly challenging for new ventures that must contend with their liabilities of newness (Navis \& Glynn, 2011; Singh, Tucker, \& House, 1986). New ventures lack access to common legitimacy signals, such as a track record of successful products (Fisher, Kotha, \& Lahiri, 2016), and often consist of little more than "elaborate fictions of proposed possible future states of existence" (Gartner, Bird, \& Starr, 1992: 17). Legitimacy therefore represents a critical precondition for new ventures' resource acquisition, growth, and survival.

\footnotetext{
${ }^{1}$ We follow the common conceptualization of legitimacy as an organizational property that is not directly observable. This understanding differs from alternative lines of research that conceptualize legitimacy as an active endorsement (e.g., Deephouse, 1996) or as a judgment by individual evaluators (e.g., Tost, 2011).
} 
Cultural entrepreneurship theory highlights entrepreneurial stories as the central driver of new ventures' legitimation and proposes that entrepreneurial stories need to achieve "optimal distinctiveness" to effectively attract resources (Lounsbury \& Glynn, 2001; Lounsbury \& Glynn, 2019; Martens, Jennings, \& Jennings, 2007; Navis \& Glynn, 2011). Within the cultural entrepreneurship framework, distinctiveness refers to the degree to which an entrepreneurial story deviates from a market category's prototypical story. Distinctiveness matters because it allows an unknown new venture to stand out and attract attention from resource-providing audiences. Yet, institutional theorists have long highlighted that distinctiveness can counteract the attainment of legitimacy (DiMaggio \& Powell, 1991). The underlying argument is that deviation from a categorical prototype reduces the comprehensibility of a proposed new venture because it prevents audiences from linking the unknown new venture to a familiar cognitive template (Navis \& Glynn, 2011). High distinctiveness can therefore prevent resource acquisition because audiences may disregard a new venture which they cannot fully comprehend. Prior research thus conceptualizes a trade-off between similarity and distinctiveness and proposes that new ventures will attract the most resources if they convey moderate degrees of distinctiveness (Lounsbury \& Glynn, 2001; Lounsbury \& Glynn, 2019; Martens et al., 2007; Navis \& Glynn, 2010; Navis \& Glynn, 2011).

In this paper, we challenge the assumption that distinctiveness necessarily counteracts the attainment of legitimacy. Foundational research in institutional theory conceptualizes legitimacy as a multi-dimensional construct (Aldrich \& Fiol, 1994; Scott, 1995; Suchman, 1995), but research on optimal distinctiveness primarily focuses on how distinctiveness threatens organizations' cognitive legitimacy - broadly defined as an organization's comprehensibility (Suchman, 1995). Yet, distinctiveness may affect a venture's normative legitimacy - i.e., its perceived congruence with the normative expectations of an audience (Suchman, 1995). Anchoring to the proposition that new venture audiences differ in their 
normative expectations (Fisher, Kuratko, Bloodgood, \& Hornsby, 2017), we suggest that distinctiveness will increase new ventures' legitimacy in the eyes of novelty-expecting audiences. When seeking resources from novelty-expecting audiences, new ventures can therefore gain legitimacy because of (and not despite) their distinctiveness. This distinction matters because it substantially alters the predicted relationship between distinctiveness and resource acquisition for novelty-expecting audiences.

We apply this theoretical proposition to examine new ventures' resource acquisition from crowdfunders - one of the most important new venture audiences (Fisher et al., 2017; Short, Ketchen, McKenny, Allison, \& Ireland, 2017). A typical new venture is more likely to attract financial contributions via Kickstarter - the largest crowdfunding platform to date - than from any venture capitalist in the world. ${ }^{2}$ We characterize crowdfunders as a novelty-expecting audience and argue that the competitive and normative benefits of distinctiveness exceed the potential cognitive liabilities of distinctiveness in the crowdfunding context. We therefore depart from prior studies on optimal distinctiveness and predict that distinctiveness has a strictly positive - rather than inverted U-shaped - effect on new ventures' resource acquisition from crowdfunders. Extending our main proposition, we further hypothesize that the legitimating effect of distinctiveness is contingent on the presence of alternative sources of normative legitimacy. Because alternative sources of legitimacy partly substitute their beneficial effects, we propose that distinctiveness will provide the greatest benefits under the absence of alternative sources of normative legitimacy.

We test our hypotheses with data from 28,425 crowdfunding campaigns across 39 market categories. We use a topic modeling approach (Hannigan et al., 2019) to identify the content patterns of crowdfunding narratives and subsequently quantify the degree to which any given

\footnotetext{
${ }^{2}$ On a global level, around 11,000 ventures attracted venture capital in 2017 according to the Venture Capital Funding Report 2017 by PricewaterhouseCoopers. In the same year, around 19,000 ventures attracted funding on Kickstarter.
} 
crowdfunding narratives deviates from the prototypical narrative in its market category. Our study provides strong evidence that the distinctiveness of entrepreneurial stories has a strictly positive effect on new ventures' resource acquisition from crowdfunders. Entrepreneurial stories with high distinctiveness attract $32 \%$ more backers and $47 \%$ higher funding pledges than those with low distinctiveness. Our study further demonstrates that the marginal benefits of distinctiveness are greatest under the absence of alternative sources of normative legitimacy. These findings strongly support our proposition that distinctiveness can provide a source of normative legitimacy and that distinctiveness thus supports - rather than weakens - the attainment of legitimacy from novelty-expecting audiences like crowdfunders.

Our theoretical propositions extend cultural entrepreneurship theory (Lounsbury \& Glynn, 2001; Lounsbury \& Glynn, 2019; Navis \& Glynn, 2011), and also contribute to the broader discussion on optimal distinctiveness in strategic management and organization theory (Barlow, Verhaal, \& Angus, 2019; Deephouse, 1999; Haans, 2019; Zhao, Fisher, Lounsbury, \& Miller, 2017; Zhao, Ishihara, Jennings, \& Lounsbury, 2018; Zuckerman, 2016). First, we disentangle the normatively and cognitively legitimating effect of entrepreneurial stories. This allows us to distinguish between normative and cognitive legitimacy as potentially opposing mechanisms in the relationship between distinctiveness and resource acquisition. Second, we uncover audiences' novelty expectations as an important boundary condition for the optimal distinctiveness trade-off. This boundary condition can explain seemingly contradictory findings about the effect of distinctiveness on demand-side performance outcomes (Barlow et al., 2019; Haans, 2019). Third, we demonstrate that the optimal degree of distinctiveness is substantially contingent on the presence of legitimating claims in entrepreneurial stories and the general public's familiarity with a market category. In doing so, we advance understanding about how entrepreneurial stories and market categories jointly legitimate new ventures. Our 
theory and empirical findings therefore provide a more nuanced understanding about why and when organizations should aim for low, moderate, or high distinctiveness.

\section{THEORY AND HYPOTHESES}

\section{Entrepreneurial Stories and the "Optimal Distinctiveness" Proposition}

Cultural entrepreneurship theory highlights the entrepreneurial story as a central antecedent of new ventures' legitimation and resource acquisition (Lounsbury, Gehman, \& Ann Glynn, 2019; Lounsbury \& Glynn, 2001; Lounsbury \& Glynn, 2019). Entrepreneurial story broadly refers to a purposefully crafted narrative about the venture. Entrepreneurial stories commonly include statements about founders' values ("We value fairness and equality"), the venture's business model ("We offer a Freemium model"), the characteristics of the market opportunity ("The demand for 3D printers is rapidly growing"), the product's technology ("Our product is built on an open-source platform"), or the product's sustainability ("Our product is fully biodegradable"). Entrepreneurial stories represent the primary touchstone for evaluations of new ventures' legitimacy because new ventures typically have limited access to other sources of legitimacy (Lounsbury \& Glynn, 2001).

One of the most popular propositions in cultural entrepreneurship has evolved under the notion of “optimal distinctiveness" (Lounsbury \& Glynn, 2001; Lounsbury \& Glynn, 2019; Martens et al., 2007) or "legitimate distinctiveness" (Navis \& Glynn, 2011). The proposition aligns with arguments in the broader discussion about how organizations can reconcile the opposing pressures for differentiation and legitimation (Deephouse, 1999; Zhao et al., 2017) but specifically focuses on distinctiveness as a property of entrepreneurial stories. As new ventures often lack access to more strategic sources of differentiation, they commonly differentiate themselves through an entrepreneurial story that deviates from the prototypical entrepreneurial story in their market category (Navis \& Glynn, 2011). Distinctiveness, however, is conceptualized as antithetical to the attainment of legitimacy. Research on optimal 
distinctiveness generally refers to the cognitive dimension of legitimacy, i.e., audiences' ability to comprehend the proposed new venture (Aldrich \& Fiol, 1994). Resource-providing audiences need to evaluate new ventures under conditions of high ambiguity - i.e., a "lack of clarity such that it is difficult to interpret or distinguish opportunities" (Davis, Eisenhardt, \& Bingham, 2009: 420) - because they are generally unfamiliar with the resource-seeking new ventures (Elsbach \& Kramer, 2003; Navis \& Glynn, 2011). Existing studies have shown that ambiguity negatively affects ventures' cognitive legitimacy from different audiences, such as investors (Martens et al., 2007) and consumers (Pontikes, 2012). New ventures become less ambiguous when they conform to a category's prototype because audiences can more easily comprehend an unknown new venture when they can locate it in a familiar category (Suchman, 1995). For instance, Elsbach and Kramer (2003) showed how Hollywood producers evaluate movie pitches much more favorably when they can cognitively match a movie with an existing category prototype. An entrepreneurial story that is similar to the category's prototype legitimates because it helps the audience to easily recognize the venture as "one of those" (Bitektine, 2011). Cognitively linking the unknown new venture to a familiar category generally reduces ambiguities about the venture (Lounsbury \& Glynn, 2001; Navis \& Glynn, 2011). Conversely, entrepreneurial stories that deviate strongly from the category's prototype lead to strong ambiguity about the venture. Prototype similarity thus supports perceptions of cognitive legitimacy, while prototype distinctiveness is expected to reduce a venture's cognitive legitimacy (Glynn \& Navis, 2013; Navis \& Glynn, 2010; Navis \& Glynn, 2011; Wry, Lounsbury, \& Glynn, 2011). The conceptualized mechanisms suggest that entrepreneurial stories attract most resources when they balance the competitive benefits (from differentiation) against the cognitive liabilities (from reduced cognitive legitimacy) of distinctiveness. 


\section{Entrepreneurial Stories as Sources of Normative Legitimacy}

Entrepreneurial stories can also serve as sources of normative legitimacy. Normative legitimacy refers to an organization's perceived congruence with the normative expectations in its institutional environment (Scott, 1995). Ventures gain normative legitimacy, also referred to as moral legitimacy (Suchman, 1995) or socio-political legitimacy (Aldrich \& Fiol, 1994), when audiences perceive them to engage in "the right thing to do" (Suchman, 1995: 579). In their original formulation of cultural entrepreneurship theory, Lounsbury and Glynn (2001) suggested that normative legitimation represents a major function of entrepreneurial stories. "To function effectively, the content of entrepreneurial stories must align with audience interests and normative beliefs to enable favorable interpretations of a new venture." (Lounsbury \& Glynn, 2001: 550). Entrepreneurial stories can support perceptions of normative legitimacy through claims that convey the venture's congruence with an audience's normative expectations (Lounsbury \& Glynn, 2001). Whether an entrepreneurial story will normatively legitimate a venture thus depends on audiences' expectations about what it means to "do the right thing" within an institutional context.

Audiences differ in their normative expectations about appropriate behaviors, and these expectations shape their legitimacy evaluations (Fisher et al., 2017). While audiences are associated with different types of expectations, we focus on audiences' novelty expectations. We define novelty expectations as the degree to which an audience expects a venture's offering and business model to be novel or unique. ${ }^{3}$ Audiences with a high novelty expectation - which we call novelty-expecting audiences - will more likely evaluate a venture as legitimate if they perceive it as novel.

\footnotetext{
${ }^{3}$ We subsequently use the term novelty - as a property of a new venture - to refer to the novelty of a venture's offering and business model. This property is distinctive from ventures' newness. All new ventures are, by definition, new but they are not necessarily novel.
} 
We propose that ventures will more likely gain normative legitimacy in the eyes of a noveltyexpecting audience when their entrepreneurial story is distinctive from the categorical prototype. New ventures often lack objective signals to convey their novelty (Rindova, Petkova, \& Kotha, 2007), and a distinctive entrepreneurial story will consequently provide an important touchstone for audiences' novelty perceptions. Distinctiveness can therefore represent a source of legitimacy when new ventures seek resources from novelty-expecting audiences. This implies that distinctiveness can unfold detrimental effects on new ventures' legitimacy by simultaneously reducing a venture's cognitive legitimacy while increasing its normative legitimacy. Distinctiveness will unfold a positive net effect on a venture's legitimacy if the normative benefits exceed the cognitive liabilities of distinctiveness.

This insight has important implications for the "optimal distinctiveness" proposition as it challenges the assumption that distinctiveness necessarily counteracts the attainment of legitimacy. We therefore depart from the common assumption new ventures necessarily face a trade-off between differentiation and legitimation. We propose that the relationship between distinctiveness and resource acquisition is mediated by three mechanisms - normative legitimacy, cognitive legitimacy, and differentiation - and that the shape of the relationship depends on the relative strength of these three mechanisms in a given context.

\section{Research Context and Hypotheses}

We test our theoretical propositions by examining new ventures' resource acquisition from crowdfunders - one of the most important audiences for new ventures (Agrawal, Catalini, \& Goldfarb, 2014; Short et al., 2017; Younkin \& Kuppuswamy, 2018). Crowdfunders are individuals that support ventures financially in exchange for tangible and intangible perks such as early access to innovative products (Mollick, 2014; Short et al., 2017). ${ }^{4}$ Following other

\footnotetext{
${ }^{4}$ Broader definitions of crowdfunding also include crowdinvesting and crowdlending (e.g., Short et al., 2017), in which ventures offer equity stakes or seek loans via online pitches. We follow the more narrow definition of
} 
studies that derive context-specific hypotheses (e.g., Wry, Lounsbury, \& Jennings, 2014), we first consulted archival materials to gain an understanding of the norms and expectations of our focal audience, crowdfunders. Among others, we analyzed discussions between crowdfunders on KickstarterForum.org, an online forum in which users of Kickstarter - the largest crowdfunding platform to date - discuss a large range of crowdfunding-related topics, including their motivations for backing specific crowdfunding campaigns.

Previous research suggests that crowdfunders are more likely to provide resources to a crowdfunding-seeking venture when they perceive it as novel and creative (Calic \& Mosakowski, 2016). Many statements on KickstarterForum.org support this finding. For instance, one user of the forum explains that "I view Kickstarter as a department store that sells unique products that you may not see the likes of anywhere else." ${ }^{5}$ Another crowdfunder states: "I really like innovative and creative technology and being able to say I was one of the first to have supported the project." A crowdfunder that had already contributed to more than 250 crowdfunding campaigns explains that the campaigns she selects "always have something unique that we don't see every day." In addition, Kickstarter potentially reinforces crowdfunders' expectation for novelty by explicitly prohibiting crowdfunding campaigns for causes that do not involve a novel product or service (e.g., philanthropic donations). Kickstarter claims that crowdfunders use their platform to find something unique as opposed to "ordering something that already exists" (Kickstarter, 2019). Prior research and qualitative evidence thus suggest that crowdfunders represent a novelty-expecting audience.

Distinctiveness and Resource Acquisition from Crowdfunders. We will now turn our attention to the normative benefits, cognitive liabilities, and competitive benefits of

crowdfunding, also referred to as rewards-based crowdfunding (Mollick, 2014), in which crowdfunders do not receive any equity stakes or repayments in exchange for their financial contributions.

${ }^{5}$ The presented quotes are derived from publicly available answers of 276 crowdfunders to the question: How many projects have you backed and why do you back them? (KickstarterForum.org, 2018). We corrected minor orthographic mistakes in the quotes. 
distinctiveness in the context of crowdfunding. Anchoring to the observation that crowdfunders have high novelty expectations, we expect that distinctiveness will positively influence crowdfunders' evaluations of a venture's normative legitimacy. Crowdfunders will more likely perceive a venture as novel when its entrepreneurial story is distinctive from the prototypical story in its market category. Previous crowdfunding research suggests that crowdfundingseeking ventures rarely hold any patents or other objective signals of their novelty (Agrawal et al., 2014; Mollick, 2014) and that crowdfunders invest relatively little effort in the due diligence of crowdfunding-seeking ventures (Agrawal et al., 2014; Short et al., 2017). Hence, it seems plausible that the distinctiveness of its entrepreneurial story will affect crowdfunders' perception of a venture's novelty. The distinctiveness of entrepreneurial stories will therefore support ventures' normative legitimacy in the eyes of crowdfunders.

Distinctiveness may reduce ventures' cognitive legitimacy from crowdfunders because it creates ambiguities. Audiences with a low tolerance of ambiguity - broadly defined as "the tendency to perceive ambiguous situations as desirable" (Budner, 1962: 29) - are particularly likely to penalize an ambiguous venture (Aldrich \& Fiol, 1994). Low tolerance of ambiguity is associated with a strong need for certainty and categorization, a preference for familiarity over unfamiliarity, and a rejection of that what is different and unusual (Bochner, 1965). Micro-level research has long shown that novelty-seeking individuals demonstrate a high tolerance of ambiguity and even desire some degree of ambiguity (Farley \& Farley, 1967; Hirschman, 1980; Kahn, 1995). Such individuals also develop stronger cognitive abilities to deal with ambiguity since they are consistently exposed to novel and ambiguous situations (Budner, 1962; Hirschman, 1980). Hence, we suggest that crowdfunders - as a noveltyexpecting audience - will have a high tolerance of ambiguity and will not necessarily disregard ambiguous ventures as potential crowdfunding targets. We thus expect that distinctiveness creates relatively weak cognitive liabilities in the crowdfunding context. 
Distinctiveness further provides competitive benefits. Crowdfunding and other platformmediated online markets tend to become highly crowded because such markets have low barriers to entry (Reuber \& Fischer, 2009; Taeuscher, 2019). Platform-mediated online markets are therefore prone to become "so crowded and noisy that it is difficult to distinguish one particular firm from its rivals" (Reuber \& Fischer, 2009: 369). Crowded markets generally exhibit a high pressure for differentiation (Taeuscher, 2019), which suggests that crowdfunding-seeking ventures will derive competitive benefits from differentiation. As in other contexts, a distinctive entrepreneurial story can provide a major source of differentiation for crowdfunding-seeking ventures and, consequently, allows ventures to attract attention from crowdfunders. Hence, we expect that distinctiveness will provide substantial competitive benefits for crowdfunding-seeking ventures.

In summary, we expect that there exist substantial normative and competitive benefits of distinctiveness and that these benefits exceed the cognitive liabilities of distinctiveness in the crowdfunding context. We thus depart from prior optimal distinctiveness research, which commonly predicts a curvilinear relationship between distinctiveness and desirable performance outcomes (e.g., Deephouse, 1999), and hypothesize:

\section{Hypothesis 1. Distinctiveness has a positive effect on new ventures' resource acquisition from crowdfunders.}

Normatively Legitimating Claims. Ventures can further gain normative legitimacy through claims that resonate with audiences' normative expectations (Lounsbury \& Glynn, 2001). Fisher et al. (2017) propose that the audience of crowdfunders abides by community norms ${ }^{6}$ and that crowdfunding-seeking ventures can consequently gain legitimacy from crowdfunders

\footnotetext{
${ }^{6}$ In this context, the term community refers both to the platform-specific crowdfunding community (e.g., Kickstarter community) and to a group of people that will derive benefits from the venture's products or services (e.g., minorities, elderly).
} 
through contribution claims - claims that "reflect the contribution the venture will make to the community and how it will provide value to the members of that community" (Fisher et al., 2017: 59). The collected qualitative evidence supports this proposition and suggests that crowdfunders prefer ventures that deliver some form of social benefit. For instance, one crowdfunder states that "I especially love to back do-good projects. It's my way of giving back to a world in which there is so much negativity." Another crowdfunder explicitly states how these normative expectations influence her crowdfunding behavior: "Some projects totally blow my mind regardless of whether I need the rewards or not. Some I simply have no connection within my realm, but the genuine presentation from the creator and the feeling that it will, on the net, bring goodness to the world will nudge my mouse towards the "pledge" button." We thus expect that contribution claims in entrepreneurial stories provide an additional source of normative legitimacy. Entrepreneurial stories with contribution claims will more likely resonate with crowdfunders and will increase the likelihood that a venture is perceived as an appropriate recipient of crowdfunding. We thus hypothesize:

Hypothesis 2. Contribution claims have a positive effect on new ventures' resource acquisition from crowdfunders.

Crowdfunders will thus infer a venture's normative appropriateness from entrepreneurial stories' distinctiveness and contribution claims. The legitimating effects of these sources of normative legitimacy are, however, not necessarily additive (Zimmerman \& Zeitz, 2002). The relationship between legitimacy and resource acquisition is generally characterized by a 'range of acceptability' (Deephouse, 1999: 152). Once a venture has reached an audience's 'range of acceptability' (Deephouse, 1999), it is considered as legitimate and will derive only marginal benefits from additional sources of legitimacy. The potential benefits of legitimacy are also bounded because legitimacy does not provide a source of differentiation (Deephouse, Bundy, Tost, \& Suchman, 2017). Once an audience perceives a venture as 
sufficiently legitimate, it will turn its attention to other criteria to evaluate and compare those organizations that are perceived as legitimate (Deephouse \& Carter, 2005).

If a venture can tap into different sources of legitimacy and the positive consequences of legitimacy are bounded, then ventures will benefit from any source of legitimacy only until they have reached their audience's 'range of acceptability.' We thus propose that the benefits derived from multiple sources of normative legitimacy will - at least partially - substitute each other. Hence, distinctiveness and contribution claims overlap in their function as sources of legitimacy. A venture that is perceived as sufficiently legitimate due to many contribution claims will face relatively low pressure to gain legitimacy through distinctiveness. This implies that the legitimating effect of distinctiveness is strongest under the absence of contribution claims and decreases at higher levels of contribution claims. We therefore hypothesize:

\section{Hypothesis 3. Contribution claims have a negative moderating effect on the positive relationship between distinctiveness and new ventures' resource acquisition from crowdfunders.}

Market category familiarity. Crowdfunders may further infer a proposed venture's novelty from the market category in which it is situated. A key proposition in cultural entrepreneurship theory is that market categories shape perceptions of new ventures (Navis \& Glynn, 2010). We focus on market category familiarity - the degree to which a market category is familiar to the general public - as an important property of market categories. The familiarity of a market category tends to increase as a category emerges and grows. ${ }^{7}$ Anchoring to the proposition that crowdfunders are a novelty-expecting audience, we propose that crowdfunders are more likely to perceive a venture as an appropriate crowdfunding target if it operates in a market category

\footnotetext{
${ }^{7}$ The general public tends to become more familiar with market categories as they emerge and grow. However, low category familiarity does not necessarily imply category newness. For instance, the general public was still relatively unfamiliar with the category of $3 \mathrm{D}$ printing when Kickstarter launched its crowdfunding platform in 2009, even though the 3D printing technology exists since 1986 (Dormehl, 2019).
} 
that lacks familiarity (i.e., is relatively unfamiliar to the general public). Under the absence of more relevant information, crowdfunders will perceive members of unfamiliar market categories as more novel than those in familiar ones. Membership in a market category with low category familiarity will therefore provide an additional source of normative legitimacy for crowdfunding-seeking ventures.

Extending our previous arguments about the moderating effect of alternative sources of legitimacy, we expect that a venture's membership in an unfamiliar market category will partly substitute the normatively legitimating effect of distinctiveness. As a consequence, we expect that high category familiarity will increase ventures' pressure to convey novelty through a distinctive entrepreneurial story. Hence, distinctiveness will provide stronger normative benefits in market categories that are highly familiar (versus unfamiliar) to the general public. We thus hypothesize:
Hypothesis 4. Market category familiarity has a positive moderating effect on the relationship between distinctiveness and new ventures' resource acquisition from crowdfunders.

Figure 1 graphically summarizes our research model.

$$
\text { --- Insert figure } 1 \text { about here --- }
$$

\section{METHODS}

\section{Data and Sample}

We chose data from Kickstarter, the largest rewards-based crowdfunding platform, which allows us to gather a representative set of crowdfunding campaigns. Since the launch of Kickstarter in April 2009, 14 million crowdfunders have jointly contributed more than 3.5 billion dollars to ventures that sought funding via the platform (Kickstarter.com, 2018). On Kickstarter, ventures fall into a basic category (e.g., technology) and a subordinate category 
(e.g., 3D printing). Subordinate categories likely provide audiences with a more meaningful cognitive anchor for comprehending a proposed venture and evaluating its novelty. In other words, we assume that crowdfunders will more likely understand and evaluate a 3D printing venture by comparing it to the prototypical 3D printing venture rather than a prototypical technology venture. We thus consider Kickstarter's subordinate categories as market categories.

To ensure external validity, we aimed to construct a sample that would represent the heterogeneity of market categories within crowdfunding platforms. Previous research suggests that audiences may differ in their expectations and evaluations of ventures in technological and non-technological categories (e.g., Fisher et al., 2016). We thus included all market categories from the basic category of technology in our sample $(\mathrm{N}=15)$. To include ventures from nontechnological categories, we chose to include all market categories from the basic categories of art $(\mathrm{N}=12)$, food $(\mathrm{N}=5)$, and theater $(\mathrm{N}=7)$. We selected those basic categories as they represent both product-centric and service-centric ventures. Many art campaigns offer tangible products in exchange for crowdfunding (e.g., a painting), whereas food and theater campaigns usually offer non-tangible rewards (e.g., crowdfunders can attend a theater play). Kickstarter provides an application programming interface (API) and maintains a public record of all successful and unsuccessful crowdfunding campaigns. The full data availability for successfully and unsuccessfully funded campaigns allowed us to overcome a potential survivorship bias, which presents a common empirical challenge in the field of entrepreneurship. We used Kickstarter's API to identify all campaigns in these preselected market categories and gather their campaign-related data points. While Kickstarter operates in several countries, we focus only on US-based campaigns to (a) ensure meaningful textual analysis and (b) eliminate bias from the lagged launch of Kickstarter in other countries. Our 
sample therefore consists of all US-based crowdfunding campaigns that were launched between May 2009 and September 2017 in the selected 39 market categories.

On Kickstarter, ventures craft a self-description in narrative form, and this description is prominently displayed on their crowdfunding campaign's web page. We used a web-crawling algorithm to gather ventures' crowdfunding narratives. After preliminary data analysis, we eliminated extreme outliers by excluding campaigns with either more than 100,000 backers, a funding goal of more than ten million dollars, a narrative of fewer than 50 words as well as those campaigns that had previously been launched under the same name by the same individuals. The final sample consists of 28,425 campaigns, spread across all 50 U.S. States.

\section{Dependent Variables}

Our dependent variable is the number of backers that pledge crowdfunding to a venture during its crowdfunding campaign. New ventures launch rewards-based crowdfunding campaigns to attract financial and non-financial resources. Among others, crowdfunding campaigns allow new ventures to develop social capital and attract awareness for their product or service (Butticè, Colombo, \& Wright, 2017; Mollick, 2014). Attracting many different crowdfunders as backers can also legitimate new ventures to other audiences such as professional investors (Fisher et al., 2017). The number of backers consequently provides a suited proxy for resource acquisition in our context because it reflects the acquisition of both financial and non-financial resources. We use the natural logarithm of the number of backers to reduce the measure's relatively high degree of skewness (Calic \& Mosakowski, 2016). In robustness tests, we further used the log amount of pledged funding (funding) as an alternative dependent variable.

\section{Independent Variables}

Distinctiveness. Distinctiveness represents the degree to which the content of an entrepreneurial story deviates from the content of the market category's prototypical 
entrepreneurial story. We used Latent Dirichlet Allocation (LDA), the most popular and commonly applied topic modeling technique (Hannigan et al., 2019; Schwarz, 2018), to identify common topics in crowdfunding narratives and subsequently represent each crowdfunding narrative as a probabilistic representation of these topics. Such a representation allows quantifying multi-dimensional constructs like distinctiveness (Haans, 2019) or novelty (Kaplan \& Vakili, 2015) in a reliable and context-authentic manner (Hannigan et al., 2019). Appendix A1 provides background information about LDA and our main parameter choices in the topic modeling procedure. Most importantly, we followed previous research (Haans, 2019; Kaplan \& Vakili, 2015) and specified the number of topics to 100 to balance the trade-off between topic variation and ease of interpretation. Online appendix A2 provides an overview of all 100 topics and the 20 words that are most representative of each topic. The appendix also includes proxies for each topic's relative importance within our sample (column 2). We subsequently followed the suggested procedure by DiMaggio (2015) to validate our topic models. This validation procedure, summarized in Appendix A3, suggests that the derived topic model demonstrates high validity.

The topic model allows us to quantify the degree to which the content of an entrepreneurial story deviates from the content of the prototypical entrepreneurial story in the venture's market category. For instance, distinctiveness of a venture in the market category of $3 D$ printing would indicate the degree to which the content of a 3D printing venture's crowdfunding narrative differs from the average content of all 3D printing ventures (i.e., the prototypical entrepreneurial story of 3D printing ventures). We followed the approach by Haans (2019) and calculated distinctiveness as

$$
\sum_{T=1}^{100} \operatorname{abs}\left(\Theta_{T, i}-\bar{\Theta}_{T, M}\right)
$$


where $\Theta_{T, i}$ refers to venture $i$ 's weight for topic T and $\bar{\Theta}_{T, M}$ represents the market category $M$ 's average weight for topic T. A given venture's distinctiveness is thus calculated as the sum of absolute deviations between venture i's topic weights and the respective market category's average topic weight over 100 topics. Distinctiveness would be 0 if a given narrative would use the same topic proportions as the average narrative in the respective market category.

Contribution Claims. We used computer-aided text analysis (CATA) to measure the number of contribution claims in each crowdfunding narrative. We chose CATA because it provides a structured, systematic, and easily replicable approach for measuring theoretically derived constructs in large amounts of text documents (Short, Broberg, Cogliser, \& Brigham, 2010). We followed the multi-step CATA dictionary development process suggested by Short et al. (2010) to systematically develop and validate our instrument. Following common practice in CATA research on new ventures (Moss, Renko, Block, \& Meyskens, 2018; Moss, Short, Payne, \& Lumpkin, 2011), we started with a deductive, theory-based approach to identify words that are synonymous or similar to the our construct of interest (e.g., community). To identify these words, it is common practice to start with Rodale's (1978) The Synonymous Finder (Short et al., 2010). We further used the open-source word search engine relatedwords.org, which draws on a large database of pre-computed word vectors of frequently co-occurring words in online texts, to identify words with highly similar usage in written texts. We then extended the wordlists through an inductive approach, in which we investigated the 1000 most frequently occurring words in our sample of crowdfunding narratives. Our final dictionary consists of 57 words. We used the software package DICTION 7.1.3 to execute the dictionary.

We primarily validated the measurement instrument by comparing it to manual coding results. We provided three graduate students with the description of the theoretical construct and asked them to count the respective contribution claims in a sample of 500 crowdfunding campaigns. 
On average, the manual coding resulted in a higher absolute number of contribution claims (3.68 versus 2.17$)$ but was highly correlated with our CATA-based measure $(r=0.58, p<$ 0.001). We thus conclude that our measure provides a reliable proxy for contribution claims. Appendix B1 presents the included words in the final dictionary. Appendix B2 presents exemplary excerpts of crowdfunding narratives that contain few or many contribution claims.

We manually examined observations with a high share of contribution claims. Most of these outliers contain one of the keywords in the venture's name. To prevent a systematic bias from such outliers, we excluded all campaigns that exceeded the relative share of contribution claims by more than ten standard deviations ( $4.6 \%$ of words). This decision eliminated 35 campaigns.

Market Category Familiarity. To test hypothesis 4, we aimed to develop a measure that can represent intra-category and inter-category differences in the degree to which a market category is familiar to the general public. We operationalized market category familiarity through the volume of media coverage in leading newspapers. Media coverage is commonly considered as a good indicator of the general public's familiarity with an organization or category (Kennedy, 2008; Pollock \& Rindova, 2003; Pollock, Rindova, \& Maggitti, 2008) because the mainstream media focuses the general public's attention on certain topics and therefore shapes the degree to which the public becomes familiar with a topic (Pollock \& Rindova, 2003). Cultural entrepreneurship research has also highlighted that coverage in the mainstream media represents a central source "by which the general public learns about new and evolving market categories and products" (Navis \& Glynn, 2010: 448). We followed previous category research (e.g., Navis \& Glynn, 2010) and focused on press articles published by the New York Times and the Washington Post. ${ }^{8}$ Using the news archive LexisNexis, we searched for articles that included the market category's label - singular or plural - in their headline. As the meaning of

\footnotetext{
${ }^{8}$ Navis and Glynn (2010) additionally included articles from the Wall Street Journal. In our context, a journal with a strong business focus is likely less relevant to inform and represent the market categories' legitimation from the general public and we thus decided against including articles from this journal.
} 
market categories partly depends on their basic category (e.g., art, technology), we included only articles that mentioned the label of the basic category (including word stems like tech*) at least once in the article. This decision helped is to prevent false positives for market categories with relatively ambiguous category labels like plays (basic category: theater). While our study's observation period is 2009 to 2017, we collected and counted all articles that were published since January 1977 - the first month of data availability in the LexisNexis news archive. We choose the cumulative number of news articles (rather than the number of new articles published in a given period) to account for the path-dependent nature of category familiarity and to reduce the measure's sensitivity to short-term fluctuations in media attention. We logged the variable to reduce skew. Our resulting measure of category coverage therefore represents the logged cumulative volume of news articles about a given market category in the mainstream media up until the month in which a given venture's crowdfunding campaign has ended.

Our search revealed a total of 40,917 articles, out of which 25,331 appeared in the New York Times and 15,586 in The Washington Post. Within our study's observation period, 3.1 articles were published per category-month. The patterns in category familiarity differ widely between and within market categories. Some market categories received relatively consistent coverage over the observation period (e.g., plays), while the coverage of others increased substantially during our observation period (e.g., 3D printing). Four market categories (e.g., makerspaces) did not receive any coverage until the end of the observation period.

\section{Control Variables}

Campaign level controls. We follow prior studies (Calic \& Mosakowski, 2016; Josefy, Dean, Albert, \& Fitza, 2017; Mollick, 2014) and include eight control variables at the campaign level: funding goal, duration, staff pick, launch rank, reward levels, video, and length. Funding goal represents to the logged dollar amount a venture intends to raise with its crowdfunding 
campaign. Launch rank represents the relative entry timing of the venture in comparison to all other ventures in the sample. The launch rank is standardized to continuous values between 0 and 1 , with the earliest campaign in the sample set to a value of zero and the latest campaign set to a value of one. Kickstarter endorses some campaigns ("Projects we love") and we include staff pick as a binary measure that indicates such an endorsement. Duration represents the number of days between the launch and closing of each crowdfunding campaign. Reward levels represent the number of different rewards offered within a given crowdfunding campaign. Ventures typically offer rewards at different levels of financial contributions, ranging from purely symbolic ones at small contribution levels ("Pledge \$10 or more and we will send you a thank you note") to rewards of higher financial value ("Pledge $\$ 500$ or more and you will receive four tickets to our opening night"). Video controls for the number of videos in a crowdfunding campaign. As the number of videos is highly skewed and demonstrates an excess in zeros (i.e., many campaigns have no video), we recoded the measure as a categorical variable with four values: no video, one video, few videos (2-4 videos), and many videos (5 or more videos).

We further included length as a control variable that represents narratives' logged number of words because the length of a narrative may indicate a campaign's quality (Calic \& Mosakowski, 2016). Preliminary analyses also showed a relatively high correlation between this measure and the independent variable of contribution claims $(r=0.46)$. Using the modified Gram-Schmidt procedure (Golub \& van Loan, 1989), as implemented in STATA's orthog function (Sribney, 1998), we orthogonalized these two variables to prevent multicollinearity problems. ${ }^{9}$ In the models, we use the original measure of contribution claims and the orthogonalized measure of length.

\footnotetext{
${ }^{9}$ Orthogonalization allows to transform a set of variables into a new set of variables that are orthogonal to each other (Golub and van Loan, 1989). After the transformation, length is completely uncorrelated $(r=0.000, p=1.000)$ with both the original and transformed measure of contribution claims.
} 
Creator level controls. We further control for heterogeneity at the creator-level by including two variables: projects backed and creator projects. We control for the number of projects backed by the creator of the crowdfunding campaign (projects backed) because individuals are more likely to back projects by founders that are more active in the Kickstarter ecosystem (Josefy et al., 2017). We log-transform the value to reduce the skew from highly active creators. When visiting a crowdfunding campaign, individuals further learn about founders' crowdfunding experience in previous Kickstarter projects. We control for the number of previously launched projects by the same campaign creator (projects created) to account for differences in entrepreneurs' crowdfunding experience (Allison, Davis, Webb, \& Short, 2017).

Geographic level controls. Previous research has shown that informal institutions at the local geographic level may affect crowdfunding outcomes. Josefy et al. (2017) found that a region's artistic culture can affect whether or not ventures in this region will receive funding for artistic projects. We follow the operationalization of artistic class by Josefy et al. (2017). The measure represents the percentage of a city's population that is employed in the visual, applied, and performing arts. We use city-level data as gathered in the American Community Survey and provided by the Economic Research Service of the U.S. Department of Agriculture. We additionally include a measure for regional income to account for the fact that crowdfunders may be more likely to contribute to ventures within their geographic proximity. Ventures in economically wealthy regions may therefore be more likely to receive crowdfunding. Using data from the US Census Bureau, the measure represents the log amount of per capita income in US-dollars in the State in which the venture is based.

Market category level controls. We include dummies for each of the four basic categories to fully control for inter-category heterogeneity. These dummies can, among others, net out any unobservable heterogeneity between technological and non-technological market categories. We further control for differences in market categories' crowding because higher crowding 
likely increases the pressure for differentiation and the potential competitive benefits of distinctiveness. Crowding represents the number of campaigns that seek crowdfunding in the same market category during the month in which a given venture's campaign is ending. To prevent multicollinearity issues, we orthogonalized category coverage and crowding. Our models include the untransformed measure for category coverage and the orthogonalized measure of crowding.

Platform level controls. We further include three measures to control for inter-temporal heterogeneity from changes in Kickstarter's platform and other macro-level dynamics. The measure Kickstarter age represents the age of Kickstarter at the launch of a given campaign, expressed as the number of months since Kickstarter launched in April 2009. This measure can directly account for the legitimation of Kickstarter itself and any other macro-level effects. We further control for a specific change in Kickstarter's policies in June 2014. Before that change, Kickstarters' employees manually reviewed each venture's campaign before granting access to their crowdfunding platform. In June 2014, Kickstarter abandoned manual reviews and started to rely primarily on algorithmic checks to very that a venture complies with Kickstarter's rules. As this policy change might affect campaigns' average quality, we add a dummy variable (manual review) that equals 1 for all campaigns that registered before June 2014 and 0 otherwise. Naturally, this dummy variable correlates highly with Kickstarter age $(\beta=-0.82)$. We orthogonalized Kickstarter age and manual review to prevent potential multicollinearity problems and included the orthogonalized Kickstarter age and the untransformed dummy for manual reviews in our main models. We further recognized that there exist seasonal effects that seemingly influence crowdfunding outcomes. For instance, campaigns ending in January attract, on average, significantly more backers (152.7) than campaigns ending in February (87.3). We thus include month dummies to control for such seasonal effects. 


\section{RESULTS}

Table 1 provides descriptive statistics and correlations. Each venture attracted, on average, 128.3 backers (median=13) and 15,702 US-dollars in funding (median=\$680).

\section{--- Insert table 1 about here --- \\ --- Insert table 2 about here ---}

Table 2 presents our main analyses, in which we ran ordinary least squares (OLS) regression models for the dependent variable of backers. We calculated all models in STATA 15 and specified our regression models with robust standard errors to deal with potential heteroscedasticity (White, 1980). Analysis of the models' uncentered variation inflation factors (VIF) would detect potential multicollinearity problems. The mean VIF values of the models range between 1.4 and 2.6 (maximum individual VIF of 7.29). As only VIF values larger than 10 indicate problems with multicollinearity (Stock \& Watson, 2007), we conclude the no such problems exist in our models.

Hypothesis 1 stated that distinctiveness has a positive effect on new ventures' resource acquisition from crowdfunders. Model 1 confirms that distinctiveness has a significant and positive effect on backers $(p<0.001)$. This provides strong support for Hypothesis 1 .

Hypothesis 2 stated that contribution claims have a positive effect on new ventures' resource acquisition from crowdfunders. Model 1 demonstrates a significantly positive effect of contribution claims on backers $(\mathrm{p}<0.001)$ and therefore provides strong support for Hypothesis 2.

Hypothesis 3 stated that contribution claims negatively moderate the relationship between distinctiveness and resource acquisition. Model 2 includes an interaction term between distinctiveness and contribution claims. The model confirms that the interaction term has a significant and negative effect on backers $(\mathrm{p}<0.001)$. This finding supports our Hypothesis 3. 
Hypothesis 4 stated that market category familiarity positively moderates the relationship between distinctiveness and crowdfunding. Models 3 demonstrates that the interaction between distinctiveness and category coverage has a significantly positive effect on backers ( $p$ $<0.001)$. This provides strong support for our Hypothesis 4 .

\section{Robustness Tests and Supplementary Analyses}

We executed various tests to verify the robustness of our results, rule out alternative explanations, and quantify the effect size for the tested relationships.

Relationship between distinctiveness and backers. We first aimed to rule out the alternative hypothesis that the relationships between distinctiveness and backers would follow a curvilinear rather than linear relationship. We added the squared term of distinctiveness (distinctiveness-square) to model 1. A minimum condition for an inverted U-shaped relationship would be that distinctiveness-square has a significantly negative effect on backers. The effect on backers is negative but not statistically significant $(p=0.109)$. We subsequently tested the joint hypothesis that the relationship between distinctiveness and backers is positive at low values of distinctiveness and negative at high distinctiveness values by running the utest command in STATA (Lind \& Mehlum, 2010). The test results suggest rejecting a curvilinear relationship ( $p=0.387$ ) and consequently add further support to our Hypothesis 1 .

Alternative dependent variable. To assess the robustness our findings, we repeated our analyses using funding as the dependent variable. Following previous crowdfunding research (e.g., Calic \& Mosakowski, 2016), we measure funding as the log amount of dollars pledged to a given crowdfunding campaign. The results of these analyses, presented in Appendix C1, strongly align with the findings in our main models. All hypothesis-testing relationships are significant $(\mathrm{p}<0.001)$ and confirm the predicted directions. These findings suggest that our findings are robust across different forms of entrepreneurial resource acquisition. 
Alternative operationalization of distinctiveness. We further aimed to test whether our findings are sensitive to our chosen operationalization of distinctiveness. We first reran our models with alternative prototype specifications. We operationalized a given crowdfunding campaign's distinctiveness vis-à-vis the prototypical crowdfunding narrative (i.e., average topics across all market categories), the prototypical narratives at the level of basic categories (e.g., the prototypical narrative in technology categories), the prototypical narrative in a market category in a given year (e.g., prototypical 3D printing narrative in 2016), and the prototypical narrative in a market category in a given quarter. Appendix $\mathrm{C} 2$ shows that our findings remain consistent when we operationalize distinctiveness vis-à-vis alternative reference points. Various robustness tests further confirmed that our findings are not sensitive to the chosen number of topics in our topic model. Appendices C3 and C4 represent alternative models, in which we set the number of topics to 50 and 200, respectively. These tables, and identical analyses for the dependent variable of funding, suggests that our results are robust across different topic model specifications.

Alternative operationalization of market category familiarity. We further tested whether the moderating effect of market category familiarity is sensitive to our specification of category coverage. Online appendix C5 presents robustness tests, in which we transform the category coverage variable into a binary measure, in which a value of 0 represents low category coverage and 1 represents high category coverage (i.e., a familiar category). The models, in which we specify the threshold for high category coverage to $1,10,50,100$, or 200 news articles, demonstrate that the binary variable of high category coverage has a positive moderating effect that is statistically significant (at $p<0.001$ ). These tests further support our Hypothesis 4 .

Estimation of effect sizes. To estimate the practical significance of distinctiveness and contribution claims, we postestimated the effect of a standard deviation increase in each of these variables based on model 1. Using the listcoef command in STATA (Long \& Freese, 
2014), we find that a standard deviation increase in distinctiveness (0.15) increases the predicted log number of backers by $6.7 \%$. A standard deviation increase in contribution claims (3.1) leads to an increase of $13 \%$ in the log number of backers. We further ran Poisson regressions to estimate the absolute number of backers (and funding dollars) that an average venture could expect from low and high distinctiveness. Using STATA's margins command, we calculated the average number of backers (or funding) at fixed levels of low and high distinctiveness. We used the empirically observed minimum and maximum values for distinctiveness to specify low distinctiveness and high distinctiveness. Predictions at the fixed level of high distinctiveness lead, on average, to 145 backers and 18,686 funding dollars. This corresponds to an increase in $32 \%$ more backers and $47 \%$ more funding in comparison to the condition of low distinctiveness. These estimations demonstrate the high practical significance of distinctiveness and contribution claims.

\section{--- Insert figure 2 about here ---}

We further aimed to estimate the practical significance of our moderation effects. To do so, we predicted the number of backers at combinations of low/high distinctiveness and few/many contribution claims (based on model 2) and low/high distinctiveness and low/high category coverage (based on model 3). To meaningfully compare the size of the two moderation effects, we specified few contribution claims and low category coverage to one standard deviation below the respective sample means, and many contribution claims and high category coverage to one standard deviation above sample means. ${ }^{10}$ The marginal effect of a standard deviation increase in distinctiveness on backers is $84 \%$ weaker under the condition of many contribution claims (versus no contribution claims). For the dependent variable of funding, this marginal effect of distinctiveness is even $100 \%$ weaker under the condition of many (versus no)

\footnotetext{
${ }^{10}$ In absolute terms, these points corresponds to entrepreneurial stories with 0 and 5.2 contribution claims and market categories with 27 and 2228 cumulated news articles.
} 
contribution claims. The marginal effect of a standard deviation increase in distinctiveness is $65 \%$ (on backers) and $77 \%$ (on funding) weaker under the condition of low category coverage (versus high category coverage). These comparisons suggest that the legitimating effect of distinctiveness is greatest under the absence of alternative sources of legitimacy.

Figure 2 represents these estimations graphically. The plots present the predicted number of backers at different levels of distinctiveness and at fixed levels of few/many contribution claims (left panel) and low/high category coverage (right panel). The plots illustrate that the relationship between distinctiveness and backers is substantially contingent on contribution claims and category coverage. The left-hand plot shows that the slope of the relationship between distinctiveness and backers is steeper under the absence of contribution claims. Hence, ventures benefit more from increased distinctiveness when they lack contribution claims. The plot also illustrates the positive direct relationship between contribution claims and backers. The right-hand plot demonstrates that the marginal effect of distinctiveness is higher in more familiar market categories (i.e., categories with a high category coverage). This demonstrates that ventures in familiar market categories benefit more from distinctiveness than those in unfamiliar ones. The right-hand plot also demonstrates the negative direct effect of category coverage on backers by showing that ventures in categories with low coverage attract more backers than those in categories with high coverage - unless they have a high distinctiveness.

\section{DISCUSSION AND CONCLUSION}

\section{Contributions to research on cultural entrepreneurship and optimal distinctiveness}

The theoretical tension between categorical similarity and distinctiveness has sparked much interest in cultural entrepreneurship (Gehman \& Grimes, 2017; Lounsbury et al., 2019; Lounsbury \& Glynn, 2001; Lounsbury \& Glynn, 2019; Martens et al., 2007; Navis \& Glynn, 2011) and resulted in the proposition that entrepreneurial stories need to balance similarity and 
distinctiveness to achieve "optimal distinctiveness". This paper set out to advance the "optimal distinctiveness" proposition and apply our theoretical propositions to the context of crowdfunding.

Our study contributes primarily to the cultural entrepreneurship literature. One key contribution is that we disentangle how distinctiveness shapes the cognitive and normative dimension of organizational legitimacy. This allowed us to introduce normative legitimacy as an important mechanism that mediates the relationship between distinctiveness and resource acquisition. Cultural entrepreneurship research strongly draws on multi-dimensional conceptualizations of organizational legitimacy (Aldrich \& Fiol, 1994; Suchman, 1995) but prior discussions of optimal distinctiveness primarily focused on the cognitively legitimating effect of entrepreneurial stories (Martens et al., 2007; Navis \& Glynn, 2011). We complement this prior research by highlighting the normatively legitimating effect of entrepreneurial stories. By outlining that distinctiveness can provide a source of normative legitimacy under certain conditions, we challenge the assumption that high distinctiveness necessarily counteracts the attainment of legitimacy. One implication is that legitimacy can simultaneously unfold a negative effect on a venture's cognitive legitimacy and a positive effect on its normative legitimacy. This allowed us to advance understanding about optimal distinctiveness by highlighting that distinctiveness has a strictly positive effect on resource acquisition - as opposed to the previously theorized inverted U-shape - when the marginal benefits of distinctiveness exceed the marginal liabilities of distinctiveness at low, moderate, and high levels of distinctiveness. The relationship between distinctiveness and resource acquisition, therefore, depends on the relative size of (1) competitive benefits (differentiation), (2) normative benefits (normative legitimacy) and (3) cognitive liabilities (reduced cognitive legitimacy) that result from distinctiveness in a given institutional context. 
Our study also contributes by uncovering specific contingencies for the trade-off between categorical similarity and distinctiveness. We draw attention to the critical role of audiences' normative expectations and conceptualize novelty expectations as a relevant property of audiences. We argued that ventures need to convey their novelty to gain legitimacy in the eyes of novelty-expecting audiences like crowdfunders. Distinctive entrepreneurial stories support perceptions of a venture's novelty and ultimately make the venture more normatively legitimate to such audiences. This audience-level property therefore suggests a boundary condition for the theorized optimal distinctiveness trade-off and implies that ventures should aim for high levels of distinctiveness when seeking resources from such audiences. Our study complements previous examinations of entrepreneurial storytelling, which primarily focused on professional investors (Martens et al., 2007; Navis \& Glynn, 2011). By demonstrating how audiences' expectations shape evaluations of similarity and distinctiveness, we add weight to the claim that new venture legitimation differs between different audiences (Fisher et al., 2017).

We further emphasized that the relationship between distinctiveness and resource acquisition is contingent on the availability of other sources of legitimacy. Prior research suggested that ventures can gain legitimacy through alternative sources of legitimacy (Zimmerman \& Zeitz, 2002), which jointly help a venture to reach an audience's 'range of acceptability' (Deephouse, 1999). Additional sources of legitimacy will only provide very marginal benefits if a venture is already positioned within an audience's 'range of acceptability.' We therefore proposed that the legitimating effect of distinctiveness decreases under the presence of alternative sources of legitimacy. Our study supported this proposition by showing that the presence of contribution claims in entrepreneurial stories - a source of new venture legitimacy in crowdfunding (Fisher et al., 2017) - negatively moderates the relationship between distinctiveness and resource acquisition. Entrepreneurial stories nevertheless attract most resources when they convey high 
distinctiveness and contain many contribution claims. We further suggested that membership in an unfamiliar market category can support perceptions of novelty and will consequently provide an additional source of legitimacy to crowdfunders. Our study supported this hypothesis and showed that the familiarity of a market category positively moderates the relationship between distinctiveness and resource acquisition. Our analyses further confirmed the assumption that category familiarity has a negative direct effect on ventures' resource acquisition from crowdfunders. By emphasizing how market categories shape evaluations of normative legitimacy, we complement prior research's focus on the cognitively legitimating function of market categories (Glynn \& Navis, 2013; Lounsbury \& Glynn, 2001; Navis \& Glynn, 2010; Wry et al., 2011). Our findings about the contingent role of contribution claims and market category familiarity provide further evidence for our two main propositions: distinctiveness provides a source of legitimacy to novelty-expecting audiences and the presence of alternative sources of legitimacy will reduce the legitimating effect of distinctiveness.

Our theorization and empirical tests further advance the optimal distinctiveness discussion in strategic management and organization theory (Deephouse, 1999; Zhao et al., 2017), where prior research has neglected the role of audience perceptions as mediator between distinctiveness and organizational performance outcomes (Zhao et al., 2017). We add to this discussion by highlighting that audiences' expectations and tolerance to ambiguity shape the outcomes of (strategic) distinctiveness. Our audience-centric perspective can help explain findings that seemingly contradict the theorized trade-off between similarity and distinctiveness. For instance, the high novelty expectations and tolerance to ambiguity of mobile app users may explain why recent research finds a strictly negative relationship between the prototype similarity (i.e., non-distinctiveness) and performance of mobile apps (Barlow et al., 2019). In doing so, we extend an emerging line of optimal distinctiveness research that 
challenges the assumption that moderate levels of distinctiveness will always yield the best performance outcomes (Barlow et al., 2019; Haans, 2019; Zhao et al., 2018).

\section{Generalizability and limitations}

We suspect that our empirical findings are most generalizable to contexts in which noveltyseeking individuals or organizations make choices between a large number of competing organizations, products, or ideas. Among others, we may expect similar empirical relationships in corporate innovation contests (e.g., Boudreau, Lacetera, \& Lakhani, 2011; Piezunka \& Dahlander, 2015), in which evaluators have to choose promising ideas from a large pool of submissions. Our findings may also generalize to many cultural industries, in which competition is driven by consumers' search for novelty (e.g., Lampel, Lant, \& Shamsie, 2000) and other online marketplaces in which consumers search for novel products (e.g., app marketplaces). Within the entrepreneurial domain, our findings may directly generalize to startup competitions like Startup Battlefield, in which evaluators seek out "the most disruptive startups" (Techcrunch, 2019). Our study has conceptualized and operationalized distinctiveness as a property of entrepreneurial stories but our findings likely also generalize to other forms of differentiation, such as those based on the composition of product portfolios (Cennamo \& Santaló, 2013; Deephouse, 1999) and product features (Zhao et al., 2018), under the outlined boundary conditions.

One limitation of our chosen context and methodological approach is that it did not allow for direct measures of legitimacy. This decision is in line with existing studies on optimal distinctiveness, which also treat legitimacy as a latent mechanism (Barlow et al., 2019; Deephouse, 1999; Haans, 2019; Zhao et al., 2018). There exists broad consensus that legitimacy - as an organizational property - may not be directly observable (Deephouse et al., 2017; Suddaby, Bitektine, \& Haack, 2017). Some previous studies have, however, operationalized (normative) legitimacy by proxies such as the tenor of an organization's 
coverage by mainstream media (e.g., Lamin \& Zaheer, 2012; Vergne, 2010). Such mediabased proxies are less suited for crowdfunding-seeking ventures because ventures in their nascent stages rarely receive attention from mainstream media. ${ }^{11}$ We thus encourage future research to examine our theoretical propositions in contexts in which there exist observable proxies for normative and cognitive legitimacy or to test our proposed mechanisms experimentally.

\section{Implications for entrepreneurs and crowdfunding-seeking ventures}

Crowdfunding platforms offer new ventures an exciting environment to attract early funding and non-financial resources. Yet, this context also presents new challenges to entrepreneurs (Short et al., 2017). Our theorization and results provide useful insights for entrepreneurs who aim to attract crowdfunding. First, our study suggests that high distinctiveness provides strong benefits for crowdfunding-seeking ventures. Hence, entrepreneurs should strongly differentiate their narrative from those of other crowdfunding campaigns in the same market category. Second, entrepreneurs can increase their crowdfunding performance by including contribution claims in their entrepreneurial story. Our developed dictionary provides a list of concrete words that entrepreneurs can use to trigger perceptions of normative appropriateness among crowdfunders. Third, our finding that crowdfunding outcomes systematically differ between market categories suggests that entrepreneurs can substantially increase their resource acquisition from crowdfunders by positioning their venture in a market category that is perceived as novel.

More broadly, our findings highlight the important role of entrepreneurial stories and audience expectations. Our findings can provide entrepreneurs with a clear business case for why they

\footnotetext{
11 Alternative conceptualizations of legitimacy have resulted in different empirical operationalizations. For instance, Soublière and Gehman (2019) conceptualize legitimacy as an outcome of a legitimation process and use the amount of pledged funding as a proxy for legitimacy. Such outcome-based proxies are, however, less suited for our research purpose because they cannot account for the presence of mechanisms other than legitimation (e.g., differentiation) in explaining resource acquisition outcomes.
} 
should invest time and energy into the development of entrepreneurial stories that resonate with the norms and expectations of their audiences. Whether an entrepreneurial ventures sacrifices legitimacy by "being different" ultimately depends on the norms and expectations of its audience. In the case of novelty-expecting audiences, distinctiveness can even increase a venture's legitimacy. 
Table 1. Descriptive statistics and correlation table

\begin{tabular}{|c|c|c|c|c|c|c|c|c|c|c|c|c|c|}
\hline & Variable & Mean & SD & Min & Max & 1 & 2 & 3 & 4 & 5 & 6 & 7 & 8 \\
\hline 1 & Backers* & 2.71 & 1.90 & 0.00 & 10.59 & 1.00 & & & & & & & \\
\hline 2 & Distinctiveness & 0.71 & 0.15 & 0.25 & 1.55 & 0.21 & 1.00 & & & & & & \\
\hline 3 & Contribution claims & 2.17 & 3.08 & 0.00 & 45.00 & 0.22 & 0.12 & 1.00 & & & & & \\
\hline 4 & Category coverage* & 5.51 & 2.20 & 0.00 & 8.15 & -0.10 & -0.13 & 0.00 & 1.00 & & & & \\
\hline 5 & Launch rank & 0.50 & 0.29 & 0.00 & 1.00 & -0.03 & -0.10 & 0.03 & 0.04 & 1.00 & & & \\
\hline 6 & Funding goal* & 8.79 & 1.83 & 0.01 & 16.12 & 0.09 & 0.03 & 0.12 & 0.15 & 0.16 & 1.00 & & \\
\hline 7 & Duration & 33.65 & 12.60 & 1.00 & 91.00 & -0.04 & 0.02 & -0.01 & 0.05 & -0.05 & 0.23 & 1.00 & \\
\hline 8 & Reward levels & 7.47 & 5.45 & 0.00 & 121.00 & 0.47 & 0.16 & 0.23 & -0.05 & -0.02 & 0.14 & 0.00 & 1.00 \\
\hline 9 & Staff pick & 0.12 & 0.32 & 0.00 & 1.00 & 0.42 & 0.07 & 0.14 & -0.07 & -0.07 & 0.08 & -0.02 & 0.25 \\
\hline 10 & Length** & 0.00 & 1.00 & -5.39 & 9.94 & 0.38 & 0.25 & 0.00 & -0.04 & 0.02 & 0.24 & 0.03 & 0.33 \\
\hline 11 & Video & 0.41 & 0.61 & 0.00 & 3.00 & 0.62 & 0.16 & 0.15 & -0.09 & 0.05 & 0.01 & -0.05 & 0.32 \\
\hline 12 & Projects created & 1.06 & 1.86 & 0.00 & 89.00 & 0.03 & 0.05 & -0.03 & 0.01 & 0.09 & 0.03 & 0.03 & 0.00 \\
\hline 13 & Projects backed & 2.04 & 12.82 & 0.00 & 776.00 & 0.16 & 0.04 & 0.04 & 0.01 & 0.01 & 0.04 & 0.00 & 0.08 \\
\hline 14 & Creator team & 0.65 & 0.94 & 0.00 & 2.00 & 0.23 & 0.08 & 0.08 & -0.03 & 0.07 & 0.13 & 0.05 & 0.12 \\
\hline 15 & Regional income* & 9.31 & 0.83 & 7.25 & 10.00 & 0.13 & 0.02 & 0.04 & -0.01 & -0.01 & 0.02 & 0.01 & 0.05 \\
\hline 16 & Artistic culture & 0.30 & 0.08 & 0.09 & 0.50 & 0.17 & 0.05 & 0.03 & 0.00 & -0.04 & 0.02 & -0.01 & 0.08 \\
\hline 17 & Crowding** & 3.63 & 1.00 & 0.00 & 5.78 & -0.11 & 0.03 & -0.04 & 0.00 & -0.17 & 0.04 & -0.02 & -0.07 \\
\hline 18 & Manual review & 0.31 & 0.46 & 0.00 & 1.00 & 0.13 & 0.15 & 0.00 & -0.09 & -0.80 & -0.18 & 0.02 & 0.06 \\
\hline 19 & Kickstarter age $* *$ & 0.00 & 1.00 & -3.66 & 2.07 & 0.14 & 0.04 & 0.06 & -0.04 & 0.55 & 0.05 & -0.09 & 0.07 \\
\hline 20 & Funding* & 5.95 & 3.36 & 0 & 15.64 & 0.93 & 0.21 & 0.22 & -0.09 & -0.03 & 0.11 & -0.03 & 0.46 \\
\hline
\end{tabular}




\begin{tabular}{|c|c|c|c|c|c|c|c|c|c|c|c|c|c|}
\hline & Variable & 9 & 10 & 11 & 12 & 13 & 14 & 15 & 16 & 17 & 18 & 19 & 20 \\
\hline 9 & Staff pick & 1.00 & & & & & & & & & & & \\
\hline 10 & Length** & 0.19 & 1.00 & & & & & & & & & & \\
\hline 11 & Video & 0.31 & 0.29 & 1.00 & & & & & & & & & \\
\hline 12 & Projects created & 0.01 & 0.09 & 0.01 & 1.00 & & & & & & & & \\
\hline 13 & Projects backed & 0.08 & 0.12 & 0.10 & 0.15 & 1.00 & & & & & & & \\
\hline 14 & Creator team & 0.10 & 0.14 & 0.19 & 0.03 & 0.03 & 1.00 & & & & & & \\
\hline 15 & Regional income* & 0.09 & 0.05 & 0.09 & 0.00 & 0.03 & 0.07 & 1.00 & & & & & \\
\hline 16 & Artistic culture & 0.13 & 0.06 & 0.13 & -0.01 & 0.03 & 0.09 & 0.31 & 1.00 & & & & \\
\hline 17 & Crowding** & -0.10 & -0.04 & -0.09 & -0.03 & -0.04 & -0.02 & -0.03 & -0.02 & 1.00 & & & \\
\hline 18 & Manual review & 0.07 & 0.03 & 0.03 & -0.11 & -0.01 & -0.04 & 0.02 & 0.06 & -0.03 & 1.00 & & \\
\hline 19 & Kickstarter age** & -0.02 & 0.11 & 0.12 & 0.01 & 0.00 & 0.05 & 0.00 & -0.01 & -0.21 & 0.00 & 1.00 & \\
\hline 20 & Funding* & 0.36 & 0.37 & 0.59 & 0.01 & 0.14 & 0.21 & 0.12 & 0.16 & -0.13 & 0.13 & 0.14 & 1.00 \\
\hline
\end{tabular}

* After logarithmic transformation, ** After orthogonalization. 
Table 2. Regression results for backers

\begin{tabular}{|c|c|c|c|c|c|c|}
\hline & \multicolumn{2}{|c|}{ Model 1} & \multicolumn{2}{|c|}{ Model 2} & \multicolumn{2}{|c|}{ Model 3} \\
\hline & $\beta$ & $p$ & $\beta$ & $p$ & $\beta$ & $p$ \\
\hline Launch rank & -0.03 & 0.816 & -0.04 & 0.743 & -0.00 & 0.990 \\
\hline Funding goal & -0.01 & 0.319 & -0.01 & 0.334 & -0.00 & 0.343 \\
\hline Duration & $-0.00^{* * *}$ & 0.000 & $-0.00^{* * *}$ & 0.000 & $-0.00^{* * *}$ & 0.000 \\
\hline Reward levels & $0.07^{* * *}$ & 0.000 & $0.07^{* * *}$ & 0.000 & $0.07^{* * *}$ & 0.000 \\
\hline Staff pick & $1.06^{* * *}$ & 0.000 & $1.06^{* * *}$ & 0.000 & $1.06^{* * *}$ & 0.000 \\
\hline Length & $0.18^{* * *}$ & 0.000 & $0.18^{* * *}$ & 0.000 & $0.18^{* * *}$ & 0.000 \\
\hline Video & Included & & Included & & Included & \\
\hline Projects created & -0.00 & 0.528 & -0.00 & 0.544 & -0.00 & 0.640 \\
\hline Projects backed & $0.01^{* * *}$ & 0.000 & $0.01^{* * *}$ & 0.000 & $0.01^{* * *}$ & 0.000 \\
\hline Creator team & $0.13^{* * *}$ & 0.000 & $0.13^{* * *}$ & 0.000 & $0.13^{* * *}$ & 0.000 \\
\hline Regional income & $0.06^{* * *}$ & 0.000 & $0.06^{* * *}$ & 0.000 & $0.06^{* * *}$ & 0.000 \\
\hline Local artistic culture & $1.37^{* * *}$ & 0.000 & $1.37^{* * *}$ & 0.000 & $1.37^{* * *}$ & 0.000 \\
\hline Food $^{\dagger}$ & $0.10^{* * * *}$ & 0.001 & $0.09^{* *}$ & 0.004 & $0.12^{* * *}$ & 0.000 \\
\hline Technology $^{\dagger}$ & $0.29^{* * *}$ & 0.000 & $0.29^{* * *}$ & 0.000 & $0.29^{* * *}$ & 0.000 \\
\hline Theater $^{\dagger}$ & $0.26^{* * *}$ & 0.000 & $0.26^{* * *}$ & 0.000 & $0.28^{* * *}$ & 0.000 \\
\hline Crowding & $-0.03^{* *}$ & 0.005 & $-0.03^{* *}$ & 0.005 & $-0.02^{*}$ & 0.022 \\
\hline Manual review $=1$ & $0.43^{* * *}$ & 0.000 & $0.42^{* * *}$ & 0.000 & $0.44^{* * *}$ & 0.000 \\
\hline Kickstarter age & $0.10^{* * *}$ & 0.000 & $0.10^{* * *}$ & 0.000 & $0.10^{* * *}$ & 0.000 \\
\hline Month dummies & Included & & Included & & Included & \\
\hline Category coverage & $-0.03^{* * *}$ & 0.000 & $-0.03^{* * *}$ & 0.000 & $-0.11^{* * *}$ & 0.000 \\
\hline Distinctiveness & $0.46^{* * *}$ & 0.000 & $0.66^{* * *}$ & 0.000 & -0.20 & 0.207 \\
\hline Contribution claims & $0.04^{* * *}$ & 0.000 & $0.11^{* * *}$ & 0.000 & $0.04^{* * *}$ & 0.000 \\
\hline Distinctiveness X Contribution claims & & & $-0.10^{* * *}$ & 0.000 & & \\
\hline Distinctiveness X Category coverage & & & & & $0.12^{* * *}$ & 0.000 \\
\hline Constant & 0.08 & 0.570 & -0.05 & 0.712 & $0.51^{* *}$ & 0.002 \\
\hline$R^{2}$ & 0.558 & & 0.558 & & 0.558 & \\
\hline$P$ & 0.000 & & 0.000 & & 0.000 & \\
\hline
\end{tabular}

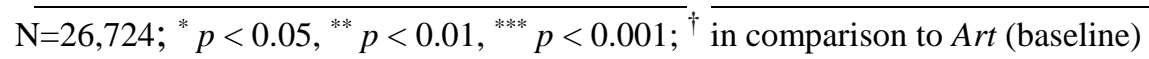


Figure 1. Research model

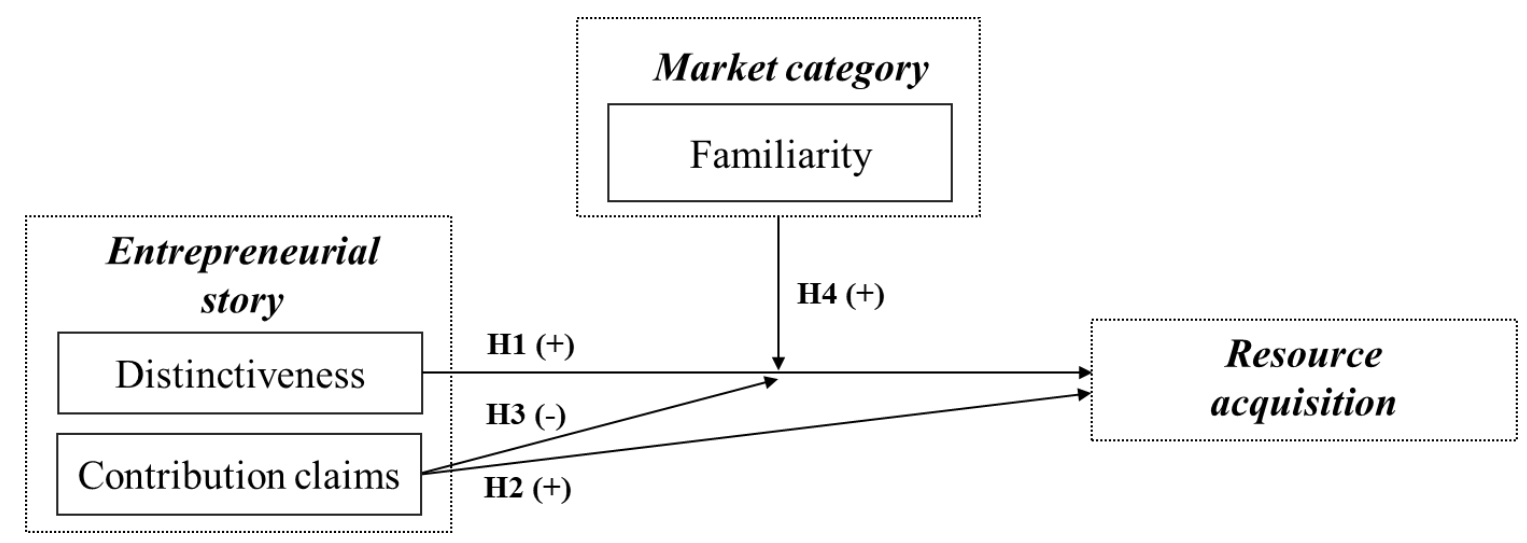

Figure 2. Relationship between distinctiveness and backers
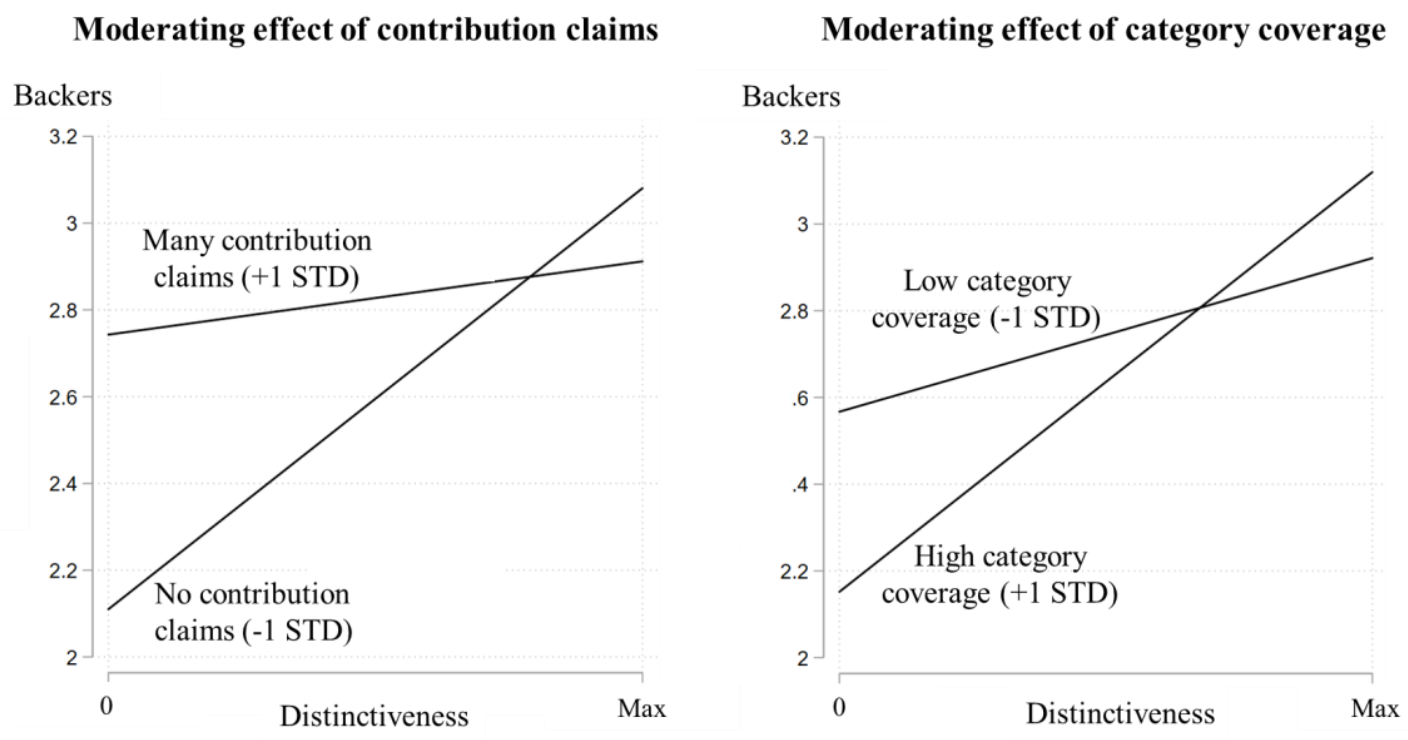


\section{References}

Agrawal, A., Catalini, C., \& Goldfarb, A. 2014. Some Simple Economics of Crowdfunding. Innovation Policy and the Economy, 14: 63-97.

Aldrich, H. E., \& Fiol, C. M. 1994. Fools Rush in? The Institutional Context of Industry Creation. Academy of Management Review, 19(4): 645-670.

Allison, T. H., Davis, B. C., Webb, J. W., \& Short, J. C. 2017. Persuasion in crowdfunding: An elaboration likelihood model of crowdfunding performance. Journal of Business Venturing, 32(6): 707-725.

Barlow, M. A., Verhaal, J. C., \& Angus, R. W. 2019. Optimal distinctiveness, strategic categorization, and product market entry on the Google Play app platform. Strategic Management Journal, 91(3): 454.

Bitektine, A. 2011. Toward a Theory of Social Judgments of Organizations: The Case of Legitimacy, Reputation, and Status. Academy of Management Review, 36(1): 151-179.

Blei, D. M., Ng, A. Y., \& Jordan, M. I. 2003. Latent dirichlet allocation. The Journal of Machine Learning Research, 3: 993-1022.

Bochner, S. 1965. Defining Intolerance of Ambiguity. The Psychological Record, 15(3): 393-400.

Boudreau, K. J., Lacetera, N., \& Lakhani, K. R. 2011. Incentives and Problem Uncertainty in Innovation Contests: An Empirical Analysis. Management Science, 57(5): 843-863.

Budner, S. N. Y. 1962. Intolerance of ambiguity as a personality variable. Journal of Personality, 30(1): 29-50.

Butticè, V., Colombo, M. G., \& Wright, M. 2017. Serial Crowdfunding, Social Capital, and Project Success. Entrepreneurship Theory and Practice, 41(2): 183-207.

Calic, G., \& Mosakowski, E. 2016. Kicking Off Social Entrepreneurship: How A Sustainability Orientation Influences Crowdfunding Success. Journal of Management Studies, 53(5): 738-767.

Cennamo, C., \& Santaló, J. 2013. Platform competition: Strategic trade-offs in platform markets. Strategic Management Journal, 34(11): 1331-1350.

Davis, J. P., Eisenhardt, K. M., \& Bingham, C. B. 2009. Optimal Structure, Market Dynamism, and the Strategy of Simple Rules. Administrative Science Quarterly, 54(3): 413-452.

Deephouse, D. L. 1999. To be different, or to be the same?: It's a question (and theory) of strategic balance. Strategic Management Journal, 20(2): 147-166.

Deephouse, D. L., Bundy, J., Tost, L. P., \& Suchman, M. C. 2017. Organizational Legitimacy: Six Key Questions. In R. Greenwood, C. Oliver, T. Lawrence \& R. E. Meyer (Eds.), The SAGE Handbook of Organizational Institutionalism (2nd ed.). Thousand Oaks CA: Sage.

Deephouse, D. L., \& Carter, S. M. 2005. An Examination of Differences Between Organizational Legitimacy and Organizational Reputation*. Journal of Management Studies, 42(2): 329-360.

DiMaggio, P. 2015. Adapting computational text analysis to social science (and vice versa). Big Data \& Society, 2(2): 205395171560290. 
DiMaggio, P., \& Powell, W. W. (Eds.). 1991. The new institutionalism in organizational analysis. Chicago: Univ. of Chicago Press.

Ellis, L. 1994. Research methods in the social sciences. Madison, Wis: Brown \& Benchmark.

Elsbach, K. D., \& Kramer, R. M. 2003. Assessing Creativity in Hollywood Pitch Meetings: Evidence for a Dual-Process Model of Creativity Judgments. Academy of Management Journal, 46(3): 283301.

Farley, F., \& Farley, S. V. 1967. Extroversion and stimulus-seeking motivation. Journal of Consulting Psychology, 31(2): 215-216.

Fisher, G., Kotha, S., \& Lahiri, A. 2016. Changing with the Times: An Integrated View of Identity, Legitimacy, and New Venture Life Cycles. Academy of Management Review, 41(3): 383-409.

Fisher, G., Kuratko, D. F., Bloodgood, J. M., \& Hornsby, J. S. 2017. Legitimate to whom?: The challenge of audience diversity and new venture legitimacy. Journal of Business Venturing, 32(1): 52-71.

Gartner, W. B., Bird, B. J., \& Starr, J. A. 1992. Acting as If: Differentiating Entrepreneurial from Organizational Behavior. Entrepreneurship Theory and Practice, 16(3): 13-32.

Gehman, J., \& Grimes, M. 2017. Hidden Badge of Honor: How Contextual Distinctiveness Affects Category Promotion Among Certified B Corporations. Academy of Management Journal, 60(6): 2294-2320.

Glynn, M. A., \& Navis, C. 2013. Categories, Identities, and Cultural Classification: Moving Beyond a Model of Categorical Constraint. Journal of Management Studies, 50(6): 1124-1137.

Golub, G. H., \& van Loan, C. F. 1989. Matrix computations (2nd ed.). Baltimore: The Johns Hopkins Univ. Press.

Griffiths, T. L., \& Steyvers, M. 2004. Finding scientific topics. Proceedings of the National Academy of Sciences of the United States of America, 101 Suppl 1: 5228-5235.

Haans, R. F. J. 2019. What's the value of being different when everyone is? The effects of distinctiveness on performance in homogeneous versus heterogeneous categories. Strategic Management Journal, 40(1): 3-27.

Hannigan, T. R., Haans, R. F. J., Vakili, K., Tchalian, H., Glaser, V. L., Wang, M. S., Kaplan, S., \& Jennings, P. D. 2019. Topic Modeling in Management Research: Rendering New Theory from Textual Data. Academy of Management Annals, 13(2): 586-632.

Hirschman, E. C. 1980. Innovativeness, Novelty Seeking, and Consumer Creativity. Journal of Consumer Research, 7(3): 283.

Josefy, M., Dean, T. J., Albert, L. S., \& Fitza, M. A. 2017. The Role of Community in Crowdfunding Success: Evidence on Cultural Attributes in Funding Campaigns to "Save the Local Theater". Entrepreneurship Theory and Practice, 41(2): 161-182.

Kahn, B. E. 1995. Consumer variety-seeking among goods and services: An integrative review. Journal of Retailing and Consumer Services, 2(3): 139-148.

Kaplan, S., \& Vakili, K. 2015. The double-edged sword of recombination in breakthrough innovation. Strategic Management Journal, 36(10): 1435-1457.

Kennedy, M. T. 2008. Getting Counted: Markets, Media, and Reality. American Sociological Review, 73(2): 270-295. 
Kickstarter. 2019. Kickstarter basics. Retrieved from https://help.kickstarter.com/hc/enus/categories/115000499013-Kickstarter-basics. Accessed 2019, July 9.

Kickstarter.com. 2018. Kickstarter Stats - Kickstarter. Retrieved from https://www.kickstarter.com/help/stats. Accessed 2018, November 5.

Lamin, A., \& Zaheer, S. 2012. Wall Street vs. Main Street: Firm Strategies for Defending Legitimacy and Their Impact on Different Stakeholders. Organization Science, 23(1): 47-66.

Lampel, J., Lant, T., \& Shamsie, J. 2000. Balancing Act: Learning from Organizing Practices in Cultural Industries. Organization Science, 11(3): 263-269.

Lind, J. T., \& Mehlum, H. 2010. With or Without U?: The Appropriate Test for a U-Shaped Relationship*. Oxford Bulletin of Economics and Statistics, 72(1): 109-118.

Long, J. S., \& Freese, J. 2014. Regression models for categorical dependent variables using Stata (3rd ed.). College Station Tex.: Stata Press.

Lounsbury, M., Gehman, J., \& Ann Glynn, M. 2019. Beyond Homo Entrepreneurus : Judgment and the Theory of Cultural Entrepreneurship. Journal of Management Studies, 7: 263.

Lounsbury, M., \& Glynn, M. A. 2001. Cultural entrepreneurship: Stories, legitimacy, and the acquisition of resources. Strategic Management Journal, 22(6-7): 545-564.

Lounsbury, M. D., \& Glynn, M. A. 2019. Cultural Entrepreneurship: A New Agenda for the Study of Entrepreneurial Processes and Possibilities: Cambridge University Press.

Martens, M. L., Jennings, J. E., \& Jennings, P. D. 2007. Do the Stories They Tell Get Them the Money They Need? The Role of Entrepreneurial Narratives in Resource Acquisition. Academy of Management Journal, 50(5): 1107-1132.

McKenny, A. F., Aguinis, H., Short, J. C., \& Anglin, A. H. 2018. What Doesn't Get Measured Does Exist: Improving the Accuracy of Computer-Aided Text Analysis. Journal of Management, 44(7): 2909-.

Mollick, E. 2014. The dynamics of crowdfunding: An exploratory study. Journal of Business Venturing, 29(1): 1-16.

Moss, T. W., Renko, M., Block, E., \& Meyskens, M. 2018. Funding the story of hybrid ventures: Crowdfunder lending preferences and linguistic hybridity. Journal of Business Venturing, (33): 643-659.

Moss, T. W., Short, J. C., Payne, G. T., \& Lumpkin, G. T. 2011. Dual Identities in Social Ventures: An Exploratory Study. Entrepreneurship Theory and Practice, 35(4): 805-830.

Navis, C., \& Glynn, M. A. 2010. How New Market Categories Emerge: Temporal Dynamics of Legitimacy, Identity, and Entrepreneurship in Satellite Radio, 1990-2005. Administrative Science Quarterly, 55(3): 439-471.

Navis, C., \& Glynn, M. A. 2011. Legitimate Distinctiveness and The Entrepreneurial Identity: Influence on Investor Judgments of New Venture Plausibility. Academy of Management Review, 36(3): 479-499.

Piezunka, H., \& Dahlander, L. 2015. Distant Search, Narrow Attention: How Crowding Alters Organizations' Filtering of Suggestions in Crowdsourcing. Academy of Management Journal, 58(3): 856-880.

Pollock, T. G., \& Rindova, V. P. 2003. Media Legitimation Effects in the Market for initial Public Offerings. Academy of Management Journal, 46(5): 631-642. 
Pollock, T. G., Rindova, V. P., \& Maggitti, P. G. 2008. Market Watch: Information and Availability Cascades Among the Media and Investors in the U.S. IPO Market. Academy of Management Journal, 51(2): 335-358.

Pontikes, E. G. 2012. Two Sides of the Same Coin: How Ambiguous Classification Affects Multiple Audiences' Evaluations. Administrative Science Quarterly, 57(1): 81-118.

Reuber, A. R., \& Fischer, E. 2009. Signalling reputation in international online markets. Strategic Entrepreneurship Journal, 3(4): 369-386.

Rindova, V. P., Petkova, A. P., \& Kotha, S. 2007. Standing out: How new firms in emerging markets build reputation. Strategic Organization, 5(1): 31-70.

Schwarz, C. 2018. Ldagibbs: A Command for Topic Modeling in Stata Using Latent Dirichlet Allocation. The Stata Journal: Promoting communications on statistics and Stata, 18(1): 101117.

Schwarz, C. 2019. Isemantica : A Stata Command for Text Similarity based on Latent Semantic Analysis. The Stata Journal, (Online before print).

Scott, W. R. 1995. Institutions and organizations: Ideas, interests and identities (1st ed.). Los Angeles, London, New Delhi, Singapore, Washington DC: Sage.

Short, J. C., Broberg, J. C., Cogliser, C. C., \& Brigham, K. H. 2010. Construct Validation Using Computer-Aided Text Analysis (CATA). Organizational Research Methods, 13(2): 320-347.

Short, J. C., Ketchen, D. J., McKenny, A. F., Allison, T. H., \& Ireland, R. D. 2017. Research on Crowdfunding: Reviewing the (Very Recent) Past and Celebrating the Present. Entrepreneurship Theory and Practice, 41(2): 149-160.

Singh, J. V., Tucker, D. J., \& House, R. J. 1986. Organizational Legitimacy and the Liability of Newness. Administrative Science Quarterly, 31(2): 171.

Soublière, J.-F., \& Gehman, J. 2019. The Legitimacy Threshold Revisited: How Prior Successes and Failures Spill Over to Other Endeavors on Kickstarter. Academy of Management Journal.

Sribney, B. 1998. ORTHOG: Stata module to orthogonalize variables. Statistical Software Components.

Stock, J. H., \& Watson, M. W. 2007. Introduction to econometrics (2nd ed.). Boston, Mass.: Pearson/Addison-Wesley.

Suchman, M. C. 1995. Managing legitimacy: Strategic and Institutional Approaches. Academy of Management Review, 20(3): 571-610.

Suddaby, R., Bitektine, A., \& Haack, P. 2017. Legitimacy. Academy of Management Annals, 11(1): 451-478.

Taeuscher, K. 2019. Reputation and new venture performance in online markets: The moderating role of market crowding. Journal of Business Venturing, (Online before print).

Vergne, J.-P. 2010. Toward a New Measure of Organizational Legitimacy: Method, Validation, and Illustration. Organizational Research Methods, 14(3): 484-502.

White, H. 1980. A Heteroskedasticity-Consistent Covariance Matrix Estimator and a Direct Test for Heteroskedasticity. Econometrica, 48(4): 817. 
Williams, U., \& Williams, S. P. 2014. Txttool: Utilities for Text Analysis in Stata. The Stata Journal: Promoting communications on statistics and Stata, 14(4): 817-829.

Wry, T., Lounsbury, M., \& Glynn, M. A. 2011. Legitimating Nascent Collective Identities: Coordinating Cultural Entrepreneurship. Organization Science, 22(2): 449-463.

Wry, T., Lounsbury, M. D., \& Jennings, J. E. 2014. Hybrid Vigor: Securing Venture Capital by Spanning Categories in Nanotechnology. Academy of Management Journal, 57(5): 1309-1333.

Younkin, P., \& Kuppuswamy, V. 2018. The Colorblind Crowd? Founder Race and Performance in Crowdfunding. Management Science, 64(7): 3269-3287.

Zhao, E. Y., Fisher, G., Lounsbury, M., \& Miller, D. 2017. Optimal distinctiveness: Broadening the interface between institutional theory and strategic management. Strategic Management Journal, 38(1): 93-113.

Zhao, E. Y., Ishihara, M., Jennings, P. D., \& Lounsbury, M. 2018. Optimal Distinctiveness in the Console Video Game Industry: An Exemplar-Based Model of Proto-Category Evolution. Organization Science, 29(4): 588-611.

Zimmerman, M. A., \& Zeitz, G. J. 2002. Beyond survival: achieving new venture growth by building legitimacy. Academy of Management Review, 27(3): 414-431.

Zuckerman, E. W. 2016. Optimal Distinctiveness Revisited: an integrative framework for understanding the balance between differentiation and conformity in individual and organizational identities. In M. G. Pratt, M. Schultz, B. E. Ashforth, D. Ravasi \& E. W. Zuckerman (Eds.), The Oxford Handbook of Organizational Identity: Oxford University Press. 


\section{Appendix A1. Background information about topic modeling approach}

Latent Dirichlet Allocation (LDA) inductively reveals topics within a specific text corpus and therefore does not require researchers to pre-specify topics in advance (Hannigan et al., 2019). LDA builds on the assumption that people use similar words when they talk about the same theme or topic. Hence, the meaning of a word in a context is relational and can be inferred from patterns of word co-occurrences within that context. LDA thus uses weighted word co-occurrences to identify topics within a text corpus and subsequently estimates probabilities that a given word represents a given topic. LDA thus treats the words in a text as probabilistic representations of the documents` cognitive content (Hannigan et al., 2019). LDA is particularly suited to deal with the fact that words can have more than one meaning and can represent more than one topic (so-called "polysemy"). By assigning probabilities that a given word is representative of a given topic, LDA does not assume mutual exclusivity between topics. Through an iterative process, LDA creates a word-topic matrix and subsequently represents each text in the text corpus as a vector of topics and their weighted probabilities (Blei, Ng, \& Jordan, 2003).

The narratives of all crowdfunding campaigns in our sample $(\mathrm{N}=28,425)$ provide our text corpus to identify common topics in crowdfunding narratives. The mean length of crowdfunding narratives in our sample is 529.6 words $(\mathrm{SD}=507$, $\min =50, \max =5224)$. Following best practices in text-based analysis, we first cleaned all texts by removing non-alphanumeric characters, a predefined list of generic words (so-called stop words) like "and" or "for" and all words that occurred in more than $50 \%$ of texts as well as words that occurred less than 10 times in the entire text corpus (Williams \& Williams, 2014). While some researchers suggest stemming or lemmatizing words in the corpus, we decided against such a transformation because there exists the substantial risk that important meaning is stripped from the words. For instance, stemming 
reduces the words operative, operating, and operational to their common stem of oper. This transformation is problematic as it omits the differences between word co-occurrences like operative and dentistry, operating and system, or operational and research (Blei, $\mathrm{Ng}$, and Jordan, 2003). After cleaning, we arrived at a corpus of 28,425 documents (D) and 17,318 unique words (W).

Researchers need to specify the number of topics to be identified by the algorithmic transformation of the document-text matrix. In contrast to numeric clustering approaches, there exist no commonly accepted rules of thumb for selecting the number of topics. Following the two studies that have used LDA for similar purposes (Haans, 2019; Kaplan \& Vakili, 2015), we specified our algorithm to identify 100 topics. Haans (2019) makes a good case that 100 topics can satisfy the demand for sufficient variance while ensuring that meaningful human interpretation is still possible. Our approach thus assumes that there exist 100 relevant topics in the institutional field of crowdfunding and that each entrepreneurial story represents a weighted configuration of these topics. We also followed previous research (Haans, 2019; Kaplan \& Vakili, 2015) in our choice of the sampling algorithm (Gibbs sampling algorithm) and the specification of the algorithm's smoothing parameters $(\alpha=0.5, \beta=0.1)$. We executed the algorithm with STATA's ldagibbs command (Schwarz, 2019). We ran 400 iterations with the sampling algorithm and reached topic convergence after around 200 iterations. We followed Griffiths and Steyvers (2004) and specified our algorithm to collect ten samples for iteratively determining the probabilities that a given word is part of a topic. 


\section{Appendix A2. Overview of topics}

\begin{tabular}{|c|c|c|c|}
\hline $\begin{array}{c}\text { Topic } \\
\text { ID }\end{array}$ & $\begin{array}{l}\text { Topic } \\
\text { loading }\end{array}$ & $\begin{array}{c}\text { Topic } \\
\text { weight }\end{array}$ & Twenty most representative words for topic \\
\hline 1 & 579.7 & $2.0 \%$ & $\begin{array}{l}\text { board, arduino, open, hardware, source, power, use, control, kit, software, project, } \\
\text { projects, controller, computer, using, electronics, boards, used, raspberry, easy }\end{array}$ \\
\hline 2 & 841.2 & $3.0 \%$ & $\begin{array}{l}\text { community, help, people, support, through, create, provide, local, world, project, } \\
\text { creative, mission, arts, share, more, social, members, non, youth, bring }\end{array}$ \\
\hline 3 & 825.9 & $2.9 \%$ & $\begin{array}{l}\text { show, dance, production, new, performance, theater, theatre, stage, play, musical, } \\
\text { festival, audience, company, music, performances, live, director, arts, actors, york }\end{array}$ \\
\hline 4 & 208.8 & $0.7 \%$ & $\begin{array}{l}\text { see, need, content, sound, capable, html, browser, playreplay, soundplay, video, } \\
\text { below, featured, action, shift, hologram, turning, stage, test, multi, dobot }\end{array}$ \\
\hline 5 & 103.6 & $0.4 \%$ & $\begin{array}{l}\text { sugar, maple, syrup, lil, sap, hickory, babs, jamb, taps, icard, clayton, tapping, boil, } \\
\text { lif, codejournals, evaporator, pan, sugaring, carvey, trucker }\end{array}$ \\
\hline 6 & 261.7 & $0.9 \%$ & $\begin{array}{l}\text { www, http, com, facebook, website, please, here, visit, check, youtube, https, more, } \\
\text { link, page, out, information, twitter, video, org, follow }\end{array}$ \\
\hline 7 & 226.3 & $0.8 \%$ & $\begin{array}{l}\text { car, vehicle, bike, ride, road, cars, truck, driving, drive, wheel bus, trailer, drivers, } \\
\text { vehicles, wheels, driver, bicycle, electric, engine, riding }\end{array}$ \\
\hline 8 & 177.3 & $0.6 \%$ & $\begin{array}{l}\text { color, black, white, red, blue, colors, green, gold, light, yellow orange, crystal, } \\
\text { patterns, pixel, silver, pink, bright, pattern, dark, purple }\end{array}$ \\
\hline 9 & 101.3 & $0.4 \%$ & $\begin{array}{l}\text { bill, mealbnb, yawning, yawn, weinie, tydrus, twit, pressed, booth, babes penny, } \\
\text { cosby, dante, rally, primarily, tip, traditional, rest, andthe, guest }\end{array}$ \\
\hline 10 & 133.8 & $0.5 \%$ & $\begin{array}{l}\text { language, texas, austin, english, word, words, houston, languages, spanish, speak, } \\
\text { speaking, dallas, french, german, russian, chinese, greek, translation, native, spoken }\end{array}$ \\
\hline 11 & 107.5 & $0.4 \%$ & $\begin{array}{l}\text { drive, drives, flash, kai, diary, raid, orphans, terma, tardisk, gamification, instincts, } \\
\text { refer, landry, minidrive, roboto, iklimt, nifty, xpress, guru, resq }\end{array}$ \\
\hline 12 & 101.6 & $0.4 \%$ & $\begin{array}{l}\text { piper, cliff, oak, alice, clara, morrison, bug, marlene, edrometer, wonderland, vanity, } \\
\text { floyd, roanoke, hydrometer, therefore, typically, based, concerns, willbe, indy }\end{array}$ \\
\hline 13 & 490.5 & $1.7 \%$ & $\begin{array}{l}\text { students, school, learn, learning, program, college, student, high, skills, education, } \\
\text { class, schools, teach, science, university, classes, technology, teaching, course, } \\
\text { experience }\end{array}$ \\
\hline 14 & 105.0 & $0.4 \%$ & $\begin{array}{l}\text { castle, pirate, rails, advice, pirates, ruby, chad, alamo, distiller, spaceup, bocco, } \\
\text { composer, cal, pony, vape, smoking, howl, roger, vaping, jolly }\end{array}$ \\
\hline 15 & 108.7 & $0.4 \%$ & $\begin{array}{l}\text { pole, corner, roller, heads, derby, reverse, dice, coaster, totem, apron, rink, moth, eva, } \\
\text { tao, hiker, boogie, tellers, hitch, acrobatic, grabber }\end{array}$ \\
\hline 16 & 103.3 & $0.4 \%$ & $\begin{array}{l}\text { dollar, cave, clown, jury, caves, sadie, albert, caverns, kennedy, abbey, kicora, dolls, } \\
\text { till, clowns, kigoma, highview, published, rain, grainy, meta }\end{array}$ \\
\hline 17 & 102.7 & $0.4 \%$ & $\begin{array}{l}\text { rob, kite, tony, kites, vikaura, dillon, anita, wyatt, nite, dodge danza, chew, chu, } \\
\text { dropship, cokes, chog, castles, corey, sean, dubstep }\end{array}$ \\
\hline 18 & 151.6 & $0.5 \%$ & $\begin{array}{l}\text { animals, animal, bees, honey, bee, horse, birds, wild, species, bear, wildlife, hive, } \\
\text { horses, hives, wolf, bird, turtle, fox, lion, elephant }\end{array}$ \\
\hline 19 & 102.4 & $0.4 \%$ & $\begin{array}{l}\text { fat, hammock, booty, alpine, awd, bro, kate, shaking, armenian, burner, naked, } \\
\text { natchez, tamales, ubi, split, gut, bros, dizmo, buster, mixcard }\end{array}$ \\
\hline 20 & 111.6 & $0.4 \%$ & $\begin{array}{l}\text { star, circle, wars, stars, massive, dna, trek, rogue, genetic, rendering, magnitude, } \\
\text { elemental, saber, lightsaber, kirk, genome, stix, roxy, spawn, stratos }\end{array}$ \\
\hline 21 & 124.8 & $0.4 \%$ & $\begin{array}{l}\text { reality, magic, virtual, experience, gear, head, cardboard, augmented, hands, } \\
\text { wrestling free, immersive, halo, viewer, display, headset, oculus, mounted, rift, } \\
\text { magician }\end{array}$ \\
\hline
\end{tabular}




\begin{tabular}{|c|c|c|c|}
\hline 22 & 102.9 & $0.4 \%$ & $\begin{array}{l}\text { microduino, whale, rare, calling, bas, tape, known, metronome, tracklinq, artcar, } \\
\text { loneliest, spiri, worlds, andthe, hybrid, glassmen, mcookie, alone, imagine, regularity }\end{array}$ \\
\hline 23 & 116.7 & $0.4 \%$ & $\begin{array}{l}\text { christmas, santa, holiday, gift, gifts, december, season, holidays, barbara, cruz, } \\
\text { advent, thanksgiving, ornaments, claus, birthdays, tree, snowflake, valentine, } \\
\text { decorations, funeral }\end{array}$ \\
\hline 24 & 121.8 & $0.4 \%$ & $\begin{array}{l}\text { los, angeles, grand, michigan, artprize, rapids, prize, entry, kevin, dia, muertos, } \\
\text { hollywood, nov, beysicair, riot, california, monica, padlock, winner, airbnb }\end{array}$ \\
\hline 25 & 425.9 & $1.5 \%$ & $\begin{array}{l}\text { history, travel, american, world, states, country, trip, state, tour, united, national, } \\
\text { america, traveling, north, south, west, along, places, journey, through }\end{array}$ \\
\hline 26 & 105.4 & $0.4 \%$ & $\begin{array}{l}\text { hawaii, hoop, hawaiian, hula, oyster, aloha, hoops, maui, sonoma, oysters ,olympia, } \\
\text { peep, honolulu, napa, kiki, mahalo, gloving, hooping, melissa, oahu }\end{array}$ \\
\hline 27 & 195.8 & $0.7 \%$ & $\begin{array}{l}\text { design, stickers, designs, shirt, shirts, sticker, graphic, vinyl, designer, logo, made, } \\
\text { cool, quality, printed, image, available, here, buttons, hands, funding }\end{array}$ \\
\hline 28 & 208.1 & $0.7 \%$ & $\begin{array}{l}\text { studio, space, wood, table, kiln, clay, tools, hand, ceramic, furniture, equipment, } \\
\text { work, shop, pieces, building, pottery, ceramics, making, small, handmade }\end{array}$ \\
\hline 29 & 108.2 & $0.4 \%$ & $\begin{array}{l}\text { circus, louis, drag, saint, cape, blake, harmony, meme, paradise, achievements, } \\
\text { charles, deaf, cod, safewallet, cage, prom, memes, england, misfits, provincetown }\end{array}$ \\
\hline 30 & 130.3 & $0.5 \%$ & $\begin{array}{l}\text { wall, mural, murals, mosaic, walls, die, tile, tiles, graffiti, mosaics, lexington, wilson, } \\
\text { madison, phoenix, bunny, prhbtn, greenville, pride, carlos, completed }\end{array}$ \\
\hline 31 & 103.7 & $0.4 \%$ & $\begin{array}{l}\text { wish, wishes, wishing, shall, granted, modi, smelt, fresco, friends, sponsors, difficult, } \\
\text { thistle, pcs, noted, fringeal, yappy, suggested, through, sigil, varying, joel }\end{array}$ \\
\hline 32 & 740.7 & $2.6 \%$ & $\begin{array}{l}\text { kickstarter, goal, project, more, new, campaign, support, stretch, pledge, rewards } \\
\text { thank, backers, first, reward, please, out, now, add, receive, here }\end{array}$ \\
\hline 33 & 1124.4 & $4.0 \%$ & $\begin{array}{l}\text { app, users, information, use, data, web, software, social, user, create, application, } \\
\text { mobile, website, time, more, site, online, platform, development, media }\end{array}$ \\
\hline 34 & 143.5 & $0.5 \%$ & $\begin{array}{l}\text { film, movie, animation, movies, films, screen, short, digital, raw, animated, projector, } \\
\text { patch, dvd, television, documentary, cinema, independent, projection, animations, } \\
\text { feature }\end{array}$ \\
\hline 35 & 232.1 & $0.8 \%$ & $\begin{array}{l}\text { sculpture, sculptures, piece, made, cast, metal, bronze, figure, model, mol,d pieces, } \\
\text { process, create, casting, figures, resin, clay, size, models, finished }\end{array}$ \\
\hline 36 & 1091.8 & $3.8 \%$ & $\begin{array}{l}\text { years, time, one, over, now, first, out, started, year, many, back, last, two, ago, few, } \\
\text { work, found, new, very, decided }\end{array}$ \\
\hline 37 & 169.4 & $0.6 \%$ & $\begin{array}{l}\text { fans, comic, character, characters, fan, convention, super, comics, con, hero favorite, } \\
\text { heroes, conventions, anime, epic, cosplay, amazing, disney, geek, action }\end{array}$ \\
\hline 38 & 209.0 & $0.7 \%$ & $\begin{array}{l}\text { children, kids, child, parents, family, fun, adults, baby, families, play, young, age, } \\
\text { toys, parent, ages, safe, kid, adult, toy, mom }\end{array}$ \\
\hline 39 & 106.4 & $0.4 \%$ & $\begin{array}{l}\text { joe, bob, volume, collecting, frank, spokane, shit, djoes, tinker, carded, yearbook, ran, } \\
\text { enter, removing, triangle, stinky, cal, viewed, pct, restore }\end{array}$ \\
\hline 40 & 106.7 & $0.4 \%$ & $\begin{array}{l}\text { spark, sam, haiti, octopus, des, secrets, odin, les, frantone, haitian, est, loki, aurora, } \\
\text { bac, pierre, happily, qui, moines, mon, pour }\end{array}$ \\
\hline 41 & 106.5 & $0.4 \%$ & $\begin{array}{l}\text { tim, soap, mama, duck, mojo, delta, chain, mouth, louisiana, domino, reaction, rouge, } \\
\text { baton, builder, tempi, soaps, armor, sasha, decoy, decoys }\end{array}$ \\
\hline 42 & 101.7 & $0.4 \%$ & $\begin{array}{l}\text { dan, pearl, donkey, minnie, cannon, kernes, noted, thermodo, inge, down, ash, center, } \\
\text { hidden, worm, tothe, sneak, willbe, dthulhu, advance, name }\end{array}$ \\
\hline 43 & 1868.9 & $6.6 \%$ & $\begin{array}{l}\text { want, people, make, out, more, one, help, know, time, need, way, see, even, } \\
\text { something, love, things, don, really, world, much }\end{array}$ \\
\hline 44 & 102.6 & $0.4 \%$ & $\begin{array}{l}\text { wake, bed, mart, clock, clocks, token, morning, sparx, wak, alarm, leela, atlantis, } \\
\text { quest, ramos, apng, mal, sharpening, wal, kathak, sharpener }\end{array}$ \\
\hline 45 & 101.5 & $0.4 \%$ & $\begin{array}{l}\text { brad, griffin, jimmy, desq, anderson, sabine, syndicate, ben, voicixx, ryan, mick, } \\
\text { persons, syracuse, diller, put, inthe, meet, hart, ubi, seeking }\end{array}$ \\
\hline
\end{tabular}




\begin{tabular}{|c|c|c|c|}
\hline 46 & 257.7 & $0.9 \%$ & $\begin{array}{l}\text { book, books, pages, reading, coloring, writing, library, poetry, page, read, cover, } \\
\text { published, write, story, written, letters, little, free, stories, magazine }\end{array}$ \\
\hline 47 & 242.9 & $0.9 \%$ & $\begin{array}{l}\text { space, flight, drone, fly, earth, flying, launch, aerial, aircraft, weather, system, moon, } \\
\text { mission, pilot, rocket, air, balloon, ground, drones, plane }\end{array}$ \\
\hline 48 & 142.0 & $0.5 \%$ & $\begin{array}{l}\text { secure, security, key, private, privacy, mail, blind, protect, password, encryption, } \\
\text { lock, storage, keys, passwords, safe, stolen, encrypted, wallet, protected, theft }\end{array}$ \\
\hline 49 & 952.0 & $3.3 \%$ & $\begin{array}{l}\text { design, use, product, designed, high, prototype, printer, made, one, using, parts, } \\
\text { quality, used, more, machine, printing, make, production, out, easy }\end{array}$ \\
\hline 50 & 136.6 & $0.5 \%$ & $\begin{array}{l}\text { war, military, veterans, veteran, gun, army, battle, combat, service, disabled, soldiers, } \\
\text { memorial, fight, served, duty, honor, soldier, men, force, guns }\end{array}$ \\
\hline 51 & 163.3 & $0.6 \%$ & $\begin{array}{l}\text { home, house, room, door, open, garage, office, doors, window, rooms, homes, } \\
\text { apartment, living, zone, houses, windows, stay, bedroom, neighbor, basement }\end{array}$ \\
\hline 52 & 197.1 & $0.7 \%$ & $\begin{array}{l}\text { safety, emergency, law, police, million, safe, situation, lives, non, risk, protect, states, } \\
\text { contact, information, dangerous, response, missing, critical, number, department }\end{array}$ \\
\hline 53 & 405.0 & $1.4 \%$ & $\begin{array}{l}\text { man, burning, fire, feet, structure, rock, playa, installation, year, project, tree, inside, } \\
\text { foot, out, built, piece, night, art, steel, build }\end{array}$ \\
\hline 54 & 111.7 & $0.4 \%$ & $\begin{array}{l}\text { island, ghost, providence, alpha, rhode, figment, treasure, governors, islands, towns, } \\
\text { coney, mining, toad, governor, newport, yono, cuba, pioneer, cuban, empty }\end{array}$ \\
\hline 55 & 114.1 & $0.4 \%$ & $\begin{array}{l}\text { phase, wind, spin, turbine, radiation, spinning, array, phases, neo, nuclear, fusion, } \\
\text { current, chimes, sweep, fidget, spins, reactor, rotating, marin, turbines }\end{array}$ \\
\hline 56 & 104.3 & $0.4 \%$ & $\begin{array}{l}\text { wedding, dino, gnome, floral, gnomes, bouquet, bride, weddings, arrangement, } \\
\text { planner, flowers, bouquets, brides, mateo, breaux, charlie, bocam, dinosaurs, groom, } \\
\text { krishna }\end{array}$ \\
\hline 57 & 164.4 & $0.6 \%$ & $\begin{array}{l}\text { party, now, people, block, page, together, public, fun, very, create, master, eye, life, } \\
\text { night, thousands, live, ddp, dance, social, doll }\end{array}$ \\
\hline 58 & 608.2 & $2.1 \%$ & $\begin{array}{l}\text { art, artists, work, artist, show, gallery, arts, space, project, new, public, exhibition, } \\
\text { works, installation, exhibit, studio, creative, museum, center, visual }\end{array}$ \\
\hline 59 & 571.5 & $2.0 \%$ & $\begin{array}{l}\text { art, painting, paintings, work, paint, project, create, artist, series, pieces, canvas, } \\
\text { piece, oil, artwork, painted, supplies, works, creating, portrait, original }\end{array}$ \\
\hline 60 & 106.4 & $0.4 \%$ & $\begin{array}{l}\text { angel, salon, nail, charm, angels, polish, nails, taos, tibetan, buddhist, thangka, toon, } \\
\text { maki, trio, spotted, tibet, klip, lama, paseo, dalai }\end{array}$ \\
\hline 61 & 106.0 & $0.4 \%$ & $\begin{array}{l}\text { richmond, cannabis, billboard, lee, billboards, spa, camino, mary, sofa, lighthouse, } \\
\text { linc, marijuana, santiago, emacs, moonlight, tillie, skibike, jfk, spakind, watershot }\end{array}$ \\
\hline 62 & 157.6 & $0.6 \%$ & $\begin{array}{l}\text { beach, sea, fish, water, ocean, boat, lake, fishing, sand, wav,e underwater, pool, } \\
\text { waves, ship, floating, swimming, salt, shore, marine, deep }\end{array}$ \\
\hline 63 & 136.8 & $0.5 \%$ & $\begin{array}{l}\text { dead, halloween, zombie, horror, haunted, monster, monsters, zombies, house, candy, } \\
\text { maze, october, attraction, blood, dark, pumpkin, haunt, escape, props, apocalypse }\end{array}$ \\
\hline 64 & 663.7 & $2.3 \%$ & $\begin{array}{l}\text { print, prints, each, paper, art, original, one, printed, limited, printing, hand, edition, } \\
\text { images, drawing, project, image, quality, color, artwork, digital }\end{array}$ \\
\hline 65 & 316.3 & $1.1 \%$ & $\begin{array}{l}\text { water, air, energy, system, clean, use, heat, temperature, hot, flow, bottle, waste, gas, } \\
\text { used, over, bag, cold, trash, environment, tank }\end{array}$ \\
\hline 66 & 168.0 & $0.6 \%$ & $\begin{array}{l}\text { medical, care, health, cancer, mental, hospital, patients, disease, patient, recovery, } \\
\text { doctors, illness, healthcare, doctor, treatment, research, therapy, hospitals, help, } \\
\text { diagnosed }\end{array}$ \\
\hline 67 & 332.1 & $1.2 \%$ & $\begin{array}{l}\text { light, power, battery, led, charge, solar, lights, usb, charging, energy, lighting, } \\
\text { batteries, charger, sun, portable, powered, panel, hours, night, high }\end{array}$ \\
\hline 68 & 893.8 & $3.1 \%$ & $\begin{array}{l}\text { phone, device, use, smart, devices, app, control, technology, iphone, smartphone, } \\
\text { one, time, mobile, bluetooth, easy, more, using, android, even, without }\end{array}$ \\
\hline 69 & 185.5 & $0.7 \%$ & $\begin{array}{l}\text { team, robot, competition, first, robotics, build, robots, teams, maker, year, } \\
\text { engineering, compete, challenge, award, lego, winning, world, competitions, design, } \\
\text { awards }\end{array}$ \\
\hline
\end{tabular}




\begin{tabular}{|c|c|c|c|}
\hline 70 & 196.2 & $0.7 \%$ & $\begin{array}{l}\text { game, games, play, sports, gaming, playing, ball, players, video, golf, team, player, } \\
\text { football, swing, field, course, sport, baseball, fans, level }\end{array}$ \\
\hline 71 & 105.3 & $0.4 \%$ & $\begin{array}{l}\text { detroit, michigan, ann, arbor, metro, hug, loveland, hugs, jerry, train, pasty, chimera, } \\
\text { consulting, legally, corktown, hugging, plymouth, detroits, detroiters, quarters }\end{array}$ \\
\hline 72 & 110.8 & $0.4 \%$ & $\begin{array}{l}\text { interview, tom, empire, holmes, effort, deviantart, old, installment, tsr, lost, efforts, } \\
\text { cubit, brand, turned, discussion, destroyed, dedicated, throne, ongoing, inthe }\end{array}$ \\
\hline 73 & 857.1 & $3.0 \%$ & $\begin{array}{l}\text { project, through, each, world, experience, create, human, between, form, one, life, } \\
\text { process, new, nature, work, way, time, different, within, piece }\end{array}$ \\
\hline 74 & 105.8 & $0.4 \%$ & $\begin{array}{l}\text { puppet, puppets, shadow, chapel, puppetry, puppeteers, smith, marionettes, } \\
\text { sunscreen, marionette solarfun, farts, fart, sundikator, bringrr, contractor, sunclipse, } \\
\text { puppeteer, twisted, twists }\end{array}$ \\
\hline 75 & 113.8 & $0.4 \%$ & $\begin{array}{l}\text { ice, snow, cream, buddy, melting, frozen, candy, pint, chair, bucket, puck, winter, } \\
\text { blower, scoop, midnight, penguin, carl, shave, cone, shanty }\end{array}$ \\
\hline 76 & 103.0 & $0.4 \%$ & $\begin{array}{l}\text { bell, emoji, radar, sentry, weighitz, emojis, probe, cocoa, cyndr, shoka, gnustep, } \\
\text { redneck, darling, jingle, onyxx, emojify, fetch, openstep, anything, slngr }\end{array}$ \\
\hline 77 & 132.9 & $0.5 \%$ & $\begin{array}{l}\text { fashion, hair, clothing, style, shoes, wear, suit, clothes, mirror, dress, skull, wearing, } \\
\text { pair, jacket, makeup, shoe, vest, skulls, gloves, ladies }\end{array}$ \\
\hline 78 & 101.7 & $0.4 \%$ & $\begin{array}{l}\text { tan, sukkah, num, tanning, enhancement, troll, fluorescent, soapbox, fluorovu, luna, } \\
\text { stl, trolls, currency, sukkot, blocklets, spectre, fluorescence, andor, cleanliness, } \\
\text { ejecting }\end{array}$ \\
\hline 79 & 127.0 & $0.4 \%$ & $\begin{array}{l}\text { dream, dreams, family, john, friends, memories, mother, life, memory, reality, loved, } \\
\text { dreaming, mom, true, jackie, lucid, father, tulsa, wife, fred }\end{array}$ \\
\hline 80 & 167.5 & $0.6 \%$ & $\begin{array}{l}\text { political, issues, vote, america, american, cube, king, rights, government, president, } \\
\text { country, public, bill, freedom, trump, voting, liberty, politics, revolution, united }\end{array}$ \\
\hline 81 & 151.3 & $0.5 \%$ & $\begin{array}{l}\text { dog, pet, beer, cat, dogs, cats, pets, craft, brewing, owners, collar, lovers, animal, } \\
\text { brewery, brew, tap, shelters, animals, rescue, kitty }\end{array}$ \\
\hline 82 & 115.3 & $0.4 \%$ & $\begin{array}{l}\text { stone, jewelry, vegas, las, stones, bracelet, stepping, necklace, beads, buddha, bead, } \\
\text { rocks, bracelets, susan, pendant, necklaces, precious, gem, grind, earrings }\end{array}$ \\
\hline 83 & 117.5 & $0.4 \%$ & $\begin{array}{l}\text { glass, glasses, coin, window, echo, torch, coins, broken, stained, windows, blowing, } \\
\text { jar, blown, ora, protector, jellyfish, ark, quarters, pennies, penny }\end{array}$ \\
\hline 84 & 705.6 & $2.5 \%$ & $\begin{array}{l}\text { food, restaurant, coffee, local, kitchen, business, open, bar, menu, family, fresh, great, } \\
\text { place, location, cooking, experience, ingredients, best, new, restaurants }\end{array}$ \\
\hline 85 & 113.9 & $0.4 \%$ & $\begin{array}{l}\text { tea, flag, rose, bubble, flags, que, del, puerto, rico, roses para, bubbles, una, los, por, } \\
\text { con, ser, como, proyecto, arte }\end{array}$ \\
\hline 86 & 113.9 & $0.4 \%$ & $\begin{array}{l}\text { hop, hip, japanese, japan, wings, buffalo, wayne, wing, tokyo, rap rosa, sake, calypso, } \\
\text { break, zing, zen, villa, jar, chris, adrian }\end{array}$ \\
\hline 87 & 629.7 & $2.2 \%$ & $\begin{array}{l}\text { city, event, new, community, local, area, events, year, public, street, san, park, space, } \\
\text { building, day, festival, place, york, neighborhood, more }\end{array}$ \\
\hline 88 & 101.3 & $0.4 \%$ & $\begin{array}{l}\text { eric, justin, clapton, fargo, babes, prove, forthe, tread, tear, grow, inthe, bath, hand, } \\
\text { each, buying, bonfire, greatest, incorporate, detaileric, familiar }\end{array}$ \\
\hline 89 & 580.7 & $2.0 \%$ & $\begin{array}{l}\text { business, company, products, product, market, website, sell, price, items, marketing, } \\
\text { store, industry, online, companies, service, small, customers, job, sales, local }\end{array}$ \\
\hline 90 & 135.1 & $0.5 \%$ & $\begin{array}{l}\text { box, machine, boxes, fabric, hat, fiber, sewing, silk, hand, cotton, yarn, puzzle, quilt, } \\
\text { textile, hats, weaving, thread, fabrics, dye, machines }\end{array}$ \\
\hline 91 & 108.1 & $0.4 \%$ & $\begin{array}{l}\text { mike, skate, daniel, skateboard, skateboarding, jeff, skating, ramp, skateboards, } \\
\text { skaters, skatepark, kamp, ramps, payne, flute, skateboarders, shred, skater, diamonds, } \\
\text { revolve }\end{array}$ \\
\hline 92 & 329.8 & $1.2 \%$ & $\begin{array}{l}\text { music, sound, audio, quality, play, sounds, speakers, song, hear, speaker, headphones, } \\
\text { radio, band, songs, guitar, recording, record, experience, listen, album }\end{array}$ \\
\hline 93 & 162.7 & $0.6 \%$ & $\begin{array}{l}\text { cards, card, deck, calendar, pin, tarot, pins, credit, greeting, decks, enamel, calendars, } \\
\text { major, playing, trading, mask, steampunk, masks, arcana, traditional }\end{array}$ \\
\hline
\end{tabular}


video, camera, photos, photo, videos, photography, capture, view, take, picture,

$94 \quad 277.7 \quad 1.0 \%$ pictures, cameras, image, images, lens, shot, see, professional, mount, quality

food, farm, garden, grow, produce, local, organic, growing, plants, land, farmers,

$95 \quad 509.7 \quad 1.8 \%$ fresh, healthy, small, plant, sustainable, grown, community, year, more

body, sleep, health, fitness, day, training, heart, brain, help, daily, time, activity,

$96 \quad 301.2 \quad 1.1 \%$ more, fit, exercise, stress, rate, workout, physical, track

help, project, need, funds, money, make, costs, goal, funding, raise, cost, more,

$97 \quad 1030.9 \quad 3.6 \%$ support, time, kickstarter, thank, equipment, pay, work, towards

maya, jade, starship, flo, congress, era, salta, ican, chop, iami, handed, roanoke, lefty,

$98 \quad 101.8 \quad 0.4 \%$ pon, liela, alexi, manual, burial, reverb, charter

life, story, women, love, stories, world, through, people, woman, god, lives, one,

$99 \quad 468.0 \quad 1.6 \%$ heart, men, hope, those, peace, girls, tell, journey

watch, apple, tag, leather, band, tags, watches, crown, wrist, click, pebble,

$100 \quad 119.1 \quad 0.4 \% \quad$ smartwatch, bands, classic, helix, stir, luxury, reserve, timepiece, swiss

Note: The first column shows the topic ID, the second column the sum of per-topic loadings (proxy for topic

importance), the third column shows the average topic share across all crowdfunding narratives, and the subsequent column contains the twenty words with the highest conditional probabilities for the topic. In other words, there exists a high likelihood that the topic manifests itself through one of these words. Additional statistics about the loadings at the level of individual words can be provided upon request. 


\section{Appendix A3. Validation of topic model}

To date, there exists no universally accepted validation method for topic models. We followed the suggestions of DiMaggio (2015) and tested whether the resulting topic model effectively deals with polysemy. DiMaggio (2015) proposes that the topic model is valid if it classifies identical words into different topics with interpretable meanings. The table below illustrates words that are highly representative of different topics. While the table is limited to three topics per word, some words occur in more topics. For instance, the word community has a high probability for five different topics. In topic 2, it co-occurs with words like help, support, provide, and project. In topic 37, it co-occurs with words like city, public, park, local, mural, building, and street. In topic 47, community co-occurs with words like food, farm, garden, grow, local, produce, organic, growing, and plants. In topic 75, the word co-occurs with words like world, life, love, and share. In topic 91, community co-occurs with words like students, school, learn, program, learning, education, student, and skills. While the meaning of these topics is a matter of interpretation, they seem to relate to different meanings of the word community, such as crowdfunding community (topic 2), neighborhood (topic 37), cooperative (topic 47), group of likeminded people (topic 75), or support group (topic 91). We thus conclude that the derived topic model demonstrates sufficient validity (DiMaggio, 2015). 


\begin{tabular}{|c|c|c|c|}
\hline Word & Co-occurrence pattern 1 & Co-occurrence pattern 2 & Co-occurrence pattern 3 \\
\hline Community & $\begin{array}{l}\text { Community, help, people, } \\
\text { support, through, create, } \\
\text { provide, local, world, } \\
\text { project, creative (\#2) }\end{array}$ & $\begin{array}{l}\text { City, event, new, local, area, } \\
\text { events, year, public, street } \\
(\# 87)\end{array}$ & $\begin{array}{l}\text { Food, farm, garden, grow, } \\
\text { produce, local, organic, } \\
\text { growing, plants, land (\#95) }\end{array}$ \\
\hline Make & $\begin{array}{l}\text { Want, people, out, more, } \\
\text { one, help, know, time, need } \\
(\# 43)\end{array}$ & $\begin{array}{l}\text { Design, use, product, } \\
\text { designed, high, prototype, } \\
\text { printer, made, one, using (\#49) }\end{array}$ & $\begin{array}{l}\text { Help, project, need, funds, } \\
\text { money, costs, goal, } \\
\text { funding, raise, (\#97) }\end{array}$ \\
\hline Product & $\begin{array}{l}\text { Design, use, product, } \\
\text { designed, high, prototype, } \\
\text { printer, made, one, using } \\
(\# 49)\end{array}$ & $\begin{array}{l}\text { Business, company, products, } \\
\text { product, market, website, sell, } \\
\text { price, items, marketing (\#89) }\end{array}$ & - \\
\hline Show & $\begin{array}{l}\text { Dance, production, new, } \\
\text { performance, theater, } \\
\text { theatre, stage, play, musical } \\
(\# 3)\end{array}$ & $\begin{array}{l}\text { Art, artists, work, artist, show, } \\
\text { gallery, arts, space, project, } \\
\text { new (\#58) }\end{array}$ & - \\
\hline Help & $\begin{array}{l}\text { Community, people, } \\
\text { support, through, create, } \\
\text { provide, local, world, project } \\
(\# 2)\end{array}$ & $\begin{array}{l}\text { Medical, care, health, cancer, } \\
\text { mental, hospital, patients, } \\
\text { disease, patient, recovery } \\
(\# 66)\end{array}$ & $\begin{array}{l}\text { Body, sleep, health, } \\
\text { fitness, day, training, heart, } \\
\text { brain, help, daily (\#96) }\end{array}$ \\
\hline World & $\begin{array}{l}\text { Community, help, people, } \\
\text { support, through, create, } \\
\text { provide, local, project, } \\
\text { creative (\#2) }\end{array}$ & $\begin{array}{l}\text { History, travel, american, } \\
\text { states, country, trip, state, tour, } \\
\text { united }(\# 25)\end{array}$ & $\begin{array}{l}\text { Life, story, women, love, } \\
\text { stories, through, people, } \\
\text { woman, god (\#99) }\end{array}$ \\
\hline
\end{tabular}

Note: The table presents exemplary words that play a central role in more than one topic. The given word and the presented words in each of the subsequent columns together represent the 10 words that have the highest probability to represent the topic for which the topic ID is provided in brackets. 


\section{Appendix B1. Wordlist for contribution claims}

\begin{tabular}{|l|l|c|}
\hline \multicolumn{1}{|c|}{ Definition } & \multicolumn{1}{c|}{ Word List } & $\begin{array}{c}\text { Inter-rater } \\
\text { agreement }\end{array}$ \\
\hline $\begin{array}{l}\text { Claims that "reflect the } \\
\text { contribution the } \\
\text { venture will make to } \\
\text { the community and } \\
\text { how it will provide } \\
\text { value to the members } \\
\text { of that community" } \\
\text { (Fisher et al., 2017: 59) }\end{array}$ & $\begin{array}{l}\text { Community, citizen, collective, commonality, } \\
\text { communal, connection, co-op, co-operative, } \\
\text { cooperative, co-partnership, family, harmony, } \\
\text { relationship, society, solidarity, companionship, } \\
\text { comradeship, connectedness, friendliness, } \\
\text { friendship, rapport, sympathy, togetherness, } \\
\text { unity, neighborhood, shared, togetherness, } \\
\text { unitedness, ethical, fair, integrity, justice, moral, } \\
\text { morality, morals, principled, principles, virtuous, } \\
\text { belong, beneficiary, caring, duty, empower, } \\
\text { equality, humanity, humankind, inspire, love, } \\
\text { peers, respect, responsibility, socially, together, } \\
\text { trust, welfare, wellbeing, well-being }\end{array}$ & 0.84 \\
\hline
\end{tabular}

Note: The inter-rater agreement reflects the theoretical validation of the measurement instrument (McKenny, Aguinis, Short, \& Anglin, 2018). Short et al. (2010) commonly followed procedure suggests dictionary validation through expert raters that are knowledgeable about the methodological requirements of CATA dictionaries and experts in the theoretical domain of interest. We selected three scholars that are experienced in CATA and had previously published on crowdfunding or entrepreneurial stories. We approached these scholars per email and asked them to decide for each keyword whether it would be representative of the construct if presented in a crowdfunding pitch. We subsequently calculated the expert raters' interrater-reliability. We used Holsti's (1969) coefficient of reliability per suggestion by Short et al. (2010). A coefficient value above 0.75 suggests high reliability (Ellis, 1994). The three experts showed an inter-rater reliability of 0.84 , and we thus consider our instrument as internally valid and reliable. Based on the experts' feedback, we eliminated seven keywords, for which two or more raters disagreed, and added three additionally suggested keywords. The table represents the final wordlist. 


\section{Appendix B2. Excerpts of crowdfunding narratives with many contribution claims}

\section{Excerpts from crowdfunding narratives with many contribution claims}

"With [name], we want to create a community for parents and families to feel comfortable, connected, safe, and confident. We want to offer the support you need by providing a space to meet new friends and visit with old, creating a center to offer co-working hours and maintaining a safe space for various support groups to meet. [...] The concept of [...] was birthed by two Portland women passionate about building community. Fiddlehead Play Collective will work hard to provide a safe space for all families by maintaining a clean, natural play space."

"The [name] is promoting creativity, kindness \& compassion through free art workshops for kids of all ages, all in the spirit of community collaboration along the way. [...] Since the beginning of my art career, directing \& participating in major public art projects has provided me a vehicle to bring more joy and beauty to thousands of people across the World. [...] This is a FREE, COMMUNITY ART PROGRAM guided by [names] who want to inspire people to treat each other the way that they themselves would like to be treated."

The [name] began with a dream I awoke from which mandated me to "make a list of people and animals you know that radiate love and joy." I immediately jotted down over 70 names, and this was just here in my own tiny community on [place]. [...] It occurred to me that I really wanted to share this upliftment with as many people as possible, and to make the project larger than just "my" art. I conceived of the "Community Wall of Love," which will involve 80 people in taking their own photos of loved ones "caught in the act of radiating love and joy."

"I am producing a new musical that deals with the subject of mental illness and how it affects people's lives in order to raise awareness and help to defeat stigmas associated with mental illnesses. My personal goal is to create more musical theatre for social justice - that is, musical theatre that raises awareness of social issues and hopefully inspires people to go out into the world and affect change. Even if it is as small as one's mindset being changed toward a group of people for the better. With that said, I begin here - with a show that discusses mental illness - because I and so many of my loved ones are sufferers of mental illness, and the stigmas associated with it can truly cripple an individual." 
Appendix C1. Regression results for funding

\begin{tabular}{|c|c|c|c|c|c|c|}
\hline \multirow[t]{2}{*}{ Funding } & \multicolumn{2}{|c|}{ Model 1} & \multicolumn{2}{|c|}{ Model 2} & \multicolumn{2}{|c|}{ Model 3} \\
\hline & $\beta$ & $P$ & $\beta$ & $p$ & $\beta$ & $p$ \\
\hline Launch rank & -0.02 & 0.920 & -0.05 & 0.806 & 0.03 & 0.874 \\
\hline Funding goal & $0.04^{* * *}$ & 0.000 & $0.04^{* * * *}$ & 0.000 & $0.04^{* * * *}$ & 0.000 \\
\hline Duration & $-0.01^{* * *}$ & 0.000 & $-0.01^{* * *}$ & 0.000 & $-0.01^{* * *}$ & 0.000 \\
\hline Reward levels & $0.14^{* * *}$ & 0.000 & $0.13^{* * *}$ & 0.000 & $0.14^{* * * *}$ & 0.000 \\
\hline Staff pick & $1.27^{* * *}$ & 0.000 & $1.26^{* * *}$ & 0.000 & $1.27^{* * *}$ & 0.000 \\
\hline Length & $0.36^{* * *}$ & 0.000 & $0.36^{* * *}$ & 0.000 & $0.36^{* * *}$ & 0.000 \\
\hline Video & Included & & Included & & Included & \\
\hline Projects created & $-0.02^{* *}$ & 0.002 & $-0.02^{* *}$ & 0.002 & $-0.02^{* *}$ & 0.005 \\
\hline Projects backed & $0.01^{* * *}$ & 0.000 & $0.01^{* * * *}$ & 0.000 & $0.01^{* * * *}$ & 0.000 \\
\hline Creator team & $0.20^{* * *}$ & 0.000 & $0.20^{* * * *}$ & 0.000 & $0.20^{* * * *}$ & 0.000 \\
\hline Regional income & $0.11^{* * *}$ & 0.000 & $0.11^{* * * *}$ & 0.000 & $0.11^{* * * *}$ & 0.000 \\
\hline Local artistic culture & $2.13^{* * *}$ & 0.000 & $2.13^{* * *}$ & 0.000 & $2.14^{* * * *}$ & 0.000 \\
\hline Food $^{\dagger}$ & $0.15^{*}$ & 0.015 & 0.11 & 0.081 & $0.20^{\text {*** }}$ & 0.002 \\
\hline Technology $y^{\dagger}$ & $0.37^{* * *}$ & 0.000 & $0.35^{* * *}$ & 0.000 & $0.35^{* * *}$ & 0.000 \\
\hline Theater $^{\dagger}$ & $0.60^{* * *}$ & 0.000 & $0.57^{* * *}$ & 0.000 & $0.63^{* * *}$ & 0.000 \\
\hline Crowding & $-0.12^{* * *}$ & 0.000 & $-0.12^{* * *}$ & 0.000 & $-0.11^{* * *}$ & 0.000 \\
\hline Manual review=1 & $0.82^{* * *}$ & 0.000 & $0.80^{* * *}$ & 0.000 & $0.84^{* * *}$ & 0.000 \\
\hline Kickstarter age & $0.17^{* * *}$ & 0.000 & $0.17^{* * * *}$ & 0.000 & $0.16^{* * *}$ & 0.000 \\
\hline Month dummies & Included & & Included & & Included & \\
\hline Category coverage & $-0.05^{* * *}$ & 0.000 & $-0.05^{* * *}$ & 0.000 & $-0.24^{* * *}$ & 0.000 \\
\hline Distinctiveness & $0.89^{* * *}$ & 0.000 & $1.46^{* * *}$ & 0.000 & -0.57 & 0.051 \\
\hline Contribution claims & $0.08^{* * * *}$ & 0.000 & $0.29^{* * *}$ & 0.000 & $0.08^{* * * *}$ & 0.000 \\
\hline $\begin{array}{l}\text { Distinctiveness X Contribution } \\
\text { claims }\end{array}$ & & & $-0.28^{* * *}$ & 0.000 & & \\
\hline $\begin{array}{l}\text { Distinctiveness X Category } \\
\text { coverage }\end{array}$ & & & & & $0.26^{* * *}$ & 0.000 \\
\hline Constant & $1.46^{* * *}$ & 0.000 & $1.08^{* * *}$ & 0.000 & $2.42^{* * *}$ & 0.000 \\
\hline$R^{2}$ & 0.500 & & 0.501 & & 0.501 & \\
\hline$p$ & 0.000 & & 0.000 & & 0.000 & \\
\hline
\end{tabular}


Appendix C2. Regression model 2 with alternative operationalization of distinctiveness

\begin{tabular}{|c|c|c|c|c|c|c|c|c|c|c|}
\hline \multirow[t]{2}{*}{ Backers } & \multicolumn{2}{|c|}{$\begin{array}{c}\text { Model } 2 \\
\text { (Distinctiveness vis-à- } \\
\text { vis market category } \\
\text { prototype; as presented } \\
\text { in main models) }\end{array}$} & \multicolumn{2}{|c|}{$\begin{array}{c}\text { Model } 2 \\
\text { (Distinctiveness vis-à- } \\
\text { vis crowdfunding } \\
\text { prototype) }\end{array}$} & \multicolumn{2}{|c|}{$\begin{array}{c}\text { Model } 2 \\
\text { (Distinctiveness vis-à- } \\
\text { vis basic category } \\
\text { prototype) }\end{array}$} & \multicolumn{2}{|c|}{$\begin{array}{c}\text { Model } 2 \\
\text { (Distinctiveness vis-à- } \\
\text { vis market category } \\
\text { prototype in respective } \\
\text { quarter) }\end{array}$} & \multicolumn{2}{|c|}{$\begin{array}{c}\text { Model } 2 \\
\text { (Distinctiveness vis-à- } \\
\text { vis market category } \\
\text { prototype in respective } \\
\text { year) }\end{array}$} \\
\hline & $\beta$ & $p$ & $B$ & $p$ & $\beta$ & $p$ & $\beta$ & $p$ & $\beta$ & $p$ \\
\hline Launch rank & -0.09 & 0.400 & -0.12 & 0.264 & -0.08 & 0.478 & -0.08 & 0.443 & -0.08 & 0.460 \\
\hline Funding goal & -0.01 & 0.122 & $-0.01^{*}$ & 0.034 & -0.01 & 0.111 & -0.01 & 0.112 & -0.01 & 0.117 \\
\hline Duration & $-0.00^{* * *}$ & 0.000 & $-0.00^{* * *}$ & 0.000 & $-0.00^{* * *}$ & 0.000 & $-0.00^{* * *}$ & 0.000 & $-0.00^{* * *}$ & 0.000 \\
\hline Reward levels & $0.08^{* * *}$ & 0.000 & $0.08^{* * *}$ & 0.000 & $0.08^{* * * *}$ & 0.000 & $0.08^{* * *}$ & 0.000 & $0.08^{* * *}$ & 0.000 \\
\hline Staff pick & $0.93^{* * *}$ & 0.000 & $0.94^{* * *}$ & 0.000 & $0.93^{* * *}$ & 0.000 & $0.94^{* * *}$ & 0.000 & $0.93^{* * *}$ & 0.000 \\
\hline Length & $0.19^{* * *}$ & 0.000 & $0.15^{* * *}$ & 0.000 & $0.18^{* * * *}$ & 0.000 & $0.19^{* * *}$ & 0.000 & $0.19^{* * *}$ & 0.000 \\
\hline Video & Included & & Included & & Included & & Included & & Included & \\
\hline Projects created & $-0.02^{* * *}$ & 0.000 & $-0.02^{* * *}$ & 0.000 & $-0.02^{* * *}$ & 0.000 & $-0.02^{* * *}$ & 0.000 & $-0.02^{* * *}$ & 0.000 \\
\hline Projects backed & $0.03^{* * * *}$ & 0.000 & $0.03^{* * *}$ & 0.000 & $0.03^{* * *}$ & 0.000 & $0.03^{* * *}$ & 0.000 & $0.03^{* * *}$ & 0.000 \\
\hline Creator team & $0.12^{* * *}$ & 0.000 & $0.11^{* * *}$ & 0.000 & $0.12^{* * * *}$ & 0.000 & $0.12^{* * *}$ & 0.000 & $0.12^{* * *}$ & 0.000 \\
\hline Regional income & $0.06^{* * *}$ & 0.000 & $0.06^{* * *}$ & 0.000 & $0.06^{* * * *}$ & 0.000 & $0.06^{* * *}$ & 0.000 & $0.06^{* * *}$ & 0.000 \\
\hline Local artistic culture & $1.23^{* * *}$ & 0.000 & $1.22^{* * *}$ & 0.000 & $1.24^{* * * *}$ & 0.000 & $1.23^{* * *}$ & 0.000 & $1.23^{* * *}$ & 0.000 \\
\hline Food $^{\dagger}$ & 0.06 & 0.062 & -0.03 & 0.278 & $0.06^{*}$ & 0.049 & $0.06^{*}$ & 0.047 & 0.06 & 0.072 \\
\hline Technology $y^{\dagger}$ & $0.17^{* * *}$ & 0.000 & $0.13^{* * *}$ & 0.000 & $0.14^{* * *}$ & 0.000 & $0.18^{* * *}$ & 0.000 & $0.17^{* * *}$ & 0.000 \\
\hline Theater $^{\dagger}$ & $0.23^{* * *}$ & 0.000 & $0.17^{* * *}$ & 0.000 & $0.28^{* * * *}$ & 0.000 & $0.23^{* * *}$ & 0.000 & $0.23^{* * *}$ & 0.000 \\
\hline Crowding & -0.02 & 0.079 & $-0.02^{*}$ & 0.043 & -0.01 & 0.149 & $-0.02^{*}$ & 0.013 & $-0.02^{*}$ & 0.043 \\
\hline Manual review $=1$ & $0.36^{* * *}$ & 0.000 & $0.33^{* * *}$ & 0.000 & $0.37^{* * *}$ & 0.000 & $0.37^{* * *}$ & 0.000 & $0.37^{* * *}$ & 0.000 \\
\hline Kickstarter age & $0.10^{* * * *}$ & 0.000 & $0.10^{* * *}$ & 0.000 & $0.10^{* * *}$ & 0.000 & $0.09^{* * *}$ & 0.000 & $0.10^{* * *}$ & 0.000 \\
\hline Month dummies & Included & & Included & & Included & & Included & & Included & \\
\hline Category coverage & $-0.03^{* * *}$ & 0.000 & $-0.03^{* * *}$ & 0.000 & $-0.03^{* * *}$ & 0.000 & $-0.03^{* * *}$ & 0.000 & $-0.03^{* * *}$ & 0.000 \\
\hline Distinctiveness & $0.59^{* * *}$ & 0.000 & $1.32^{* * *}$ & 0.000 & $0.81^{* * *}$ & 0.000 & $0.53^{* * *}$ & 0.000 & $0.54^{* * *}$ & 0.000 \\
\hline Contribution claims & $0.11^{* * * *}$ & 0.000 & $0.10^{* * *}$ & 0.000 & $0.12^{* * * *}$ & 0.000 & $0.10^{* * *}$ & 0.000 & $0.11^{* * *}$ & 0.000 \\
\hline Distinctiveness X & $-0.09^{* * *}$ & 0.000 & $-0.07^{* *}$ & 0.001 & $-0.09^{* * * *}$ & 0.000 & $-0.07^{* * * *}$ & 0.000 & $-0.08^{* * * *}$ & 0.000 \\
\hline Contribution claims & & & & & & & & & & \\
\hline Constant & 0.03 & 0.826 & $-0.52^{* * *}$ & 0.000 & -0.18 & 0.205 & 0.10 & 0.476 & 0.07 & 0.607 \\
\hline$R^{2}$ & 0.613 & & 0.616 & & 0.614 & & 0.614 & & 0.613 & \\
\hline $\mathrm{p}$ & 0.000 & & 0.000 & & 0.000 & & 0.000 & & 0.000 & \\
\hline
\end{tabular}

${ }^{*} p<0.05,{ }^{* *} p<0.01,{ }^{* * * *} p<0.001 ;{ }^{\dagger}$ in comparison to Art (baseline); Models differ only in the operationalization of Distinctiveness. 
Appendix C3. Regression models with alternative topic modeling parameter (50 topics) for backers

\begin{tabular}{|c|c|c|c|c|c|c|}
\hline \multirow[t]{2}{*}{ Backers } & \multicolumn{2}{|c|}{ Model 1} & \multicolumn{2}{|c|}{ Model 2} & \multicolumn{2}{|c|}{ Model 3} \\
\hline & $\beta$ & $p$ & $\beta$ & $p$ & $\beta$ & $p$ \\
\hline Launch rank & -0.08 & 0.462 & -0.09 & 0.403 & -0.06 & 0.578 \\
\hline Funding goal & -0.01 & 0.107 & -0.01 & 0.115 & -0.01 & 0.118 \\
\hline Duration & $-0.00^{* * * *}$ & 0.000 & $-0.00^{* * *}$ & 0.000 & $-0.00^{* * * *}$ & 0.000 \\
\hline Reward levels & $0.08^{* * * *}$ & 0.000 & $0.08^{* * * *}$ & 0.000 & $0.08^{* * * *}$ & 0.000 \\
\hline Staff pick & $0.93^{* * *}$ & 0.000 & $0.93^{* * *}$ & 0.000 & $0.93^{* * * *}$ & 0.000 \\
\hline Length & $0.19^{* * *}$ & 0.000 & $0.19^{* * * *}$ & 0.000 & $0.19^{* * *}$ & 0.000 \\
\hline Video & Included & & Included & & Included & \\
\hline Projects created & $-0.02^{* * *}$ & 0.000 & $-0.02^{* * *}$ & 0.000 & $-0.02^{* * * *}$ & 0.000 \\
\hline Projects backed & $0.03^{* * *}$ & 0.000 & $0.03^{* * * *}$ & 0.000 & $0.03^{* * * *}$ & 0.000 \\
\hline Creator team & $0.12^{* * *}$ & 0.000 & $0.12^{* * *}$ & 0.000 & $0.12^{* * * *}$ & 0.000 \\
\hline Regional income & $0.06^{* * * *}$ & 0.000 & $0.06^{* * *}$ & 0.000 & $0.06^{* * *}$ & 0.000 \\
\hline Local artistic culture & $1.22^{* * *}$ & 0.000 & $1.22^{* * *}$ & 0.000 & $1.22^{* * * *}$ & 0.000 \\
\hline Food $^{\dagger}$ & $0.07^{*}$ & 0.020 & 0.06 & 0.056 & $0.09^{* * *}$ & 0.007 \\
\hline Technology ${ }^{\dagger}$ & $0.18^{* * * *}$ & 0.000 & $0.18^{* * * *}$ & 0.000 & $0.17^{* * *}$ & 0.000 \\
\hline Theater $^{\dagger}$ & $0.22^{* * *}$ & 0.000 & $0.22^{* * *}$ & 0.000 & $0.23^{* * * *}$ & 0.000 \\
\hline Crowding & -0.02 & 0.073 & -0.02 & 0.071 & -0.01 & 0.160 \\
\hline Manual review $=1$ & $0.37^{* * *}$ & 0.000 & $0.36^{* * *}$ & 0.000 & $0.37^{* * *}$ & 0.000 \\
\hline Kickstarter age & $0.10^{* * *}$ & 0.000 & $0.10^{* * *}$ & 0.000 & $0.09^{* * *}$ & 0.000 \\
\hline Month dummies & Included & & Included & & Included & \\
\hline Category coverage & $-0.03^{\text {**** }}$ & 0.000 & $-0.03^{\text {**** }}$ & 0.000 & $-0.09^{* * * *}$ & 0.000 \\
\hline Distinctiveness & $0.30^{* * *}$ & 0.000 & $0.44^{* * * *}$ & 0.000 & -0.09 & 0.486 \\
\hline Contribution claims & $0.05^{* * *}$ & 0.000 & $0.10^{* * *}$ & 0.000 & $0.05^{* * * *}$ & 0.000 \\
\hline Distinctiveness X Contr & & & $-0.07^{* * *}$ & 0.000 & & \\
\hline Distinctiveness X Category coverage & & & & & $0.07^{* * *}$ & 0.001 \\
\hline Constant & 0.20 & 0.134 & 0.10 & 0.451 & $0.49^{* *}$ & 0.002 \\
\hline$R^{2}$ & 0.613 & & 0.613 & & 0.613 & \\
\hline $\mathrm{p}$ & 0.000 & & 0.000 & & 0.000 & \\
\hline
\end{tabular}

${ }^{*} p<0.05,{ }^{* *} p<0.01,{ }^{* * *} p<0.001 ;{ }^{\dagger}$ in comparison to Art (baseline); Models differ from main models in their operationalization of topics (50 topics instead of 100) and the resulting distinctiveness measure. 
Appendix C4. Regression models with alternative topic modeling parameter (200 topics)

\section{for backers}

\begin{tabular}{|c|c|c|c|c|c|c|}
\hline \multirow[t]{2}{*}{ Backers } & \multicolumn{2}{|c|}{ Model 1} & \multicolumn{2}{|c|}{ Model 2} & \multicolumn{2}{|c|}{ Model 3} \\
\hline & $\beta$ & $P$ & $\beta$ & $p$ & $\beta$ & $p$ \\
\hline Launch rank & -0.06 & 0.589 & -0.06 & 0.558 & -0.03 & 0.794 \\
\hline Funding goal & -0.01 & 0.128 & -0.01 & 0.134 & -0.01 & 0.143 \\
\hline Duration & $-0.00^{* * *}$ & 0.000 & $-0.00^{* * *}$ & 0.000 & $-0.00^{* * *}$ & 0.000 \\
\hline Reward levels & $0.08^{* * * *}$ & 0.000 & $0.08^{* * * *}$ & 0.000 & $0.08^{* * *}$ & 0.000 \\
\hline Staff pick & $0.93^{* * *}$ & 0.000 & $0.93^{* * *}$ & 0.000 & $0.94^{* * *}$ & 0.000 \\
\hline Length & $0.19^{* * *}$ & 0.000 & $0.19^{* * *}$ & 0.000 & $0.19^{* * * *}$ & 0.000 \\
\hline Video & Included & & Included & & Included & \\
\hline Projects created & $-0.02^{* * *}$ & 0.000 & $-0.02^{* * *}$ & 0.000 & $-0.01^{* * *}$ & 0.001 \\
\hline Projects backed & $0.03^{* * *}$ & 0.000 & $0.03^{* * *}$ & 0.000 & $0.03^{* * *}$ & 0.000 \\
\hline Creator team & $0.12^{* * *}$ & 0.000 & $0.12^{* * *}$ & 0.000 & $0.12^{* * *}$ & 0.000 \\
\hline Regional income & $0.06^{* * *}$ & 0.000 & $0.06^{* * *}$ & 0.000 & $0.06^{* * *}$ & 0.000 \\
\hline Local artistic culture & $1.22^{* * *}$ & 0.000 & $1.23^{* * *}$ & 0.000 & $1.22^{* * *}$ & 0.000 \\
\hline Food $^{\dagger}$ & $0.07^{*}$ & 0.024 & $0.06^{*}$ & 0.048 & $0.10^{* *}$ & 0.002 \\
\hline Technology $y^{\dagger}$ & $0.15^{* * *}$ & 0.000 & $0.15^{* * *}$ & 0.000 & $0.15^{* * *}$ & 0.000 \\
\hline Theater $^{\dagger}$ & $0.24^{* * *}$ & 0.000 & $0.23^{* * *}$ & 0.000 & $0.26^{* * *}$ & 0.000 \\
\hline Crowding & -0.01 & 0.130 & -0.01 & 0.127 & -0.01 & 0.255 \\
\hline Manual review=1 & $0.38^{* * *}$ & 0.000 & $0.38^{* * *}$ & 0.000 & $0.39^{* * *}$ & 0.000 \\
\hline Kickstarter age & $0.09^{* * * *}$ & 0.000 & $0.09^{* * *}$ & 0.000 & $0.09^{* * *}$ & 0.000 \\
\hline Month dummies & Included & & Included & & Included & \\
\hline Category coverage & $-0.03^{* * *}$ & 0.000 & $-0.03^{* * *}$ & 0.000 & $-0.09^{* * *}$ & 0.000 \\
\hline Distinctiveness & $0.48^{* * *}$ & 0.000 & $0.70^{* * *}$ & 0.000 & $-0.46^{*}$ & 0.014 \\
\hline Contr. claims & $0.05^{* * *}$ & 0.000 & $0.08^{* * *}$ & 0.000 & $0.05^{* * *}$ & 0.000 \\
\hline Distinctiveness X Contribution claims & & & $-0.10^{* * *}$ & 0.000 & & \\
\hline Distinctiveness X Category coverage & & & & & $0.17^{* * *}$ & 0.000 \\
\hline Constant & 0.24 & 0.073 & 0.17 & 0.215 & $0.57^{* * *}$ & 0.000 \\
\hline$R^{2}$ & 0.612 & & 0.613 & & 0.612 & \\
\hline $\mathrm{p}$ & 0.000 & & 0.000 & & 0.000 & \\
\hline
\end{tabular}

${ }^{*} p<0.05,{ }^{* *} p<0.01,{ }^{* * *} p<0.001 ;{ }^{\dagger}$ in comparison to Art (baseline). Models differ from main models in their operationalization of topics (200 topics instead of 100) and the resulting distinctiveness measure. 


\section{Appendix C5. Regression model 3 with binary operationalization of category coverage}

\begin{tabular}{|c|c|c|c|c|c|c|c|c|c|c|}
\hline \multirow[t]{2}{*}{ Backers } & \multicolumn{2}{|c|}{$\begin{array}{c}\text { Model } 3 \text { (Category } \\
\text { coverage }=1 \text { if }>0 \\
\text { news articles) }\end{array}$} & \multicolumn{2}{|c|}{$\begin{array}{c}\text { Model } 3 \text { (Category } \\
\text { coverage }=1 \text { if }>10 \\
\text { news articles) }\end{array}$} & \multicolumn{2}{|c|}{$\begin{array}{c}\text { Model } 3 \text { (Category } \\
\text { coverage }=1 \text { if }>50 \\
\text { news articles) }\end{array}$} & \multicolumn{2}{|c|}{$\begin{array}{c}\text { Model } 3 \text { (Category } \\
\text { coverage }=1 \text { if } \\
>100 \text { news articles) }\end{array}$} & \multicolumn{2}{|c|}{$\begin{array}{c}\text { Model } 3 \text { Category } \\
\text { coverage }=1 \text { if } \\
>200 \text { news articles) }\end{array}$} \\
\hline & $\beta$ & $p$ & $\beta$ & $p$ & $B$ & $p$ & $\beta$ & $p$ & $\beta$ & $p$ \\
\hline Launch rank & -0.08 & 0.455 & -0.16 & 0.153 & -0.15 & 0.176 & -0.08 & 0.441 & -0.07 & 0.504 \\
\hline Funding goal(ln) & -0.01 & 0.098 & -0.01 & 0.052 & $-0.01^{*}$ & 0.049 & -0.01 & 0.147 & -0.01 & 0.110 \\
\hline Duration & $-0.00^{* * *}$ & 0.000 & $-0.00^{* * *}$ & 0.000 & $-0.00^{* * *}$ & 0.000 & $-0.00^{* * *}$ & 0.000 & $-0.00^{* * *}$ & 0.000 \\
\hline Reward levels & $0.08^{* * *}$ & 0.000 & $0.08^{* * *}$ & 0.000 & $0.08^{* * *}$ & 0.000 & $0.08^{* * *}$ & 0.000 & $0.08^{* * *}$ & 0.000 \\
\hline Staff pick & $0.93^{* * *}$ & 0.000 & $0.93^{* * *}$ & 0.000 & $0.93^{* * *}$ & 0.000 & $0.94^{* * *}$ & 0.000 & $0.94^{* * *}$ & 0.000 \\
\hline Length & $0.19^{* * *}$ & 0.000 & $0.19^{* * *}$ & 0.000 & $0.19^{* * *}$ & 0.000 & $0.19^{* * *}$ & 0.000 & $0.19^{* * *}$ & 0.000 \\
\hline Video & Included & & Included & & Included & & Included & & Included & \\
\hline Projects created by creator & $-0.02^{* * *}$ & 0.000 & $-0.01^{* * *}$ & 0.001 & $-0.02^{* * *}$ & 0.000 & $-0.02^{* * *}$ & 0.000 & $-0.02^{* * *}$ & 0.000 \\
\hline Projects backed by creator & $0.03^{* * *}$ & 0.000 & $0.03^{* * *}$ & 0.000 & $0.03^{* * *}$ & 0.000 & $0.03^{* * *}$ & 0.000 & $0.03^{* * *}$ & 0.000 \\
\hline Creator team & $0.12^{* * *}$ & 0.000 & $0.12^{* * *}$ & 0.000 & $0.11^{* * *}$ & 0.000 & $0.12^{* * *}$ & 0.000 & $0.12^{* * *}$ & 0.000 \\
\hline Regional income & $0.06^{* * *}$ & 0.000 & $0.06^{* * *}$ & 0.000 & $0.06^{* * *}$ & 0.000 & $0.06^{* * *}$ & 0.000 & $0.06^{* * *}$ & 0.000 \\
\hline Local artistic culture & $1.22^{* * *}$ & 0.000 & $1.21^{* * *}$ & 0.000 & $1.23^{* * *}$ & 0.000 & $1.21^{* * *}$ & 0.000 & $1.21^{* * *}$ & 0.000 \\
\hline Food $^{\dagger}$ & $0.09^{* *}$ & 0.005 & $0.22^{* * * *}$ & 0.000 & $0.20^{* * *}$ & 0.000 & $0.09^{* *}$ & 0.004 & $0.11^{* * *}$ & 0.000 \\
\hline Technology $^{\dagger}$ & $0.19^{* * *}$ & 0.000 & $0.27^{* * *}$ & 0.000 & $0.22^{* * *}$ & 0.000 & $0.21^{* * *}$ & 0.000 & $0.23^{* * *}$ & 0.000 \\
\hline Theater $^{\dagger}$ & $0.25^{* * *}$ & 0.000 & $0.33^{* * *}$ & 0.000 & $0.32^{* * *}$ & 0.000 & $0.26^{* * *}$ & 0.000 & $0.29^{* * *}$ & 0.000 \\
\hline Crowding & -0.02 & 0.066 & $-0.03^{* * *}$ & 0.001 & $-0.04^{* * *}$ & 0.000 & $-0.02^{*}$ & 0.013 & -0.01 & 0.092 \\
\hline Manual review $=1$ & $0.37^{* * *}$ & 0.000 & $0.34^{* * *}$ & 0.000 & $0.36^{* * * *}$ & 0.000 & $0.35^{* * *}$ & 0.000 & $0.37^{* * *}$ & 0.000 \\
\hline Kickstarter age & $0.10^{* * *}$ & 0.000 & $0.10^{* * *}$ & 0.000 & $0.09^{* * *}$ & 0.000 & $0.10^{* * *}$ & 0.000 & $0.09^{* * *}$ & 0.000 \\
\hline Month dummies & Included & & Included & & Included & & Included & & Included & \\
\hline Category coverage & $-0.04^{* * *}$ & 0.000 & $-0.07^{* * *}$ & 0.000 & $-0.12^{* * *}$ & 0.000 & 0.01 & 0.337 & 0.01 & 0.432 \\
\hline Distinctiveness & $-0.48^{*}$ & 0.045 & -0.15 & 0.379 & 0.13 & 0.248 & 0.10 & 0.266 & 0.11 & 0.200 \\
\hline Contribution claims & $0.04^{* * *}$ & 0.000 & $0.04^{* * *}$ & 0.000 & $0.04^{* * * *}$ & 0.000 & $0.04^{* * *}$ & 0.000 & $0.04^{* * * *}$ & 0.000 \\
\hline Category coverage $=1$ & $-0.58^{* *}$ & 0.002 & 0.01 & 0.966 & $0.30^{* *}$ & 0.002 & $-0.56^{* * *}$ & 0.000 & $-0.56^{* * *}$ & 0.000 \\
\hline Distinctiveness X Category coverage $=1$ & $0.93^{* * *}$ & 0.000 & $0.59^{* *}$ & 0.001 & $0.35^{* *}$ & 0.007 & $0.50^{* * *}$ & 0.000 & $0.51^{* * *}$ & 0.000 \\
\hline Constant & $0.75^{* * *}$ & 0.001 & $0.47^{* *}$ & 0.009 & $0.57^{* * *}$ & 0.000 & $0.31^{*}$ & 0.033 & 0.26 & 0.075 \\
\hline Adjusted $R^{2}$ & 0.613 & & 0.614 & & 0.617 & & 0.613 & & 0.612 & \\
\hline $\mathrm{p}$ & 0.000 & & 0.000 & & 0.000 & & 0.000 & & 0.000 & \\
\hline
\end{tabular}

${ }^{*} \frac{\mathrm{p}}{p<0.05,{ }^{* *} p<0.01,{ }^{* * *} p<0.001} ; \dagger+i$ in comparison to Art (baseline). Models differ from main models in the operationalization of category coverage (binary). 
Karl Taeuscher (Karl.Taeuscher@manchester.ac.uk) is a Lecturer in Strategic Management and Entrepreneurship at the Alliance Manchester Business School, University of Manchester. His research interests include new venture legitimation and growth, competition between and within online platforms, business model innovation, narratives, reputation and status, as well as market emergence.

Ricarda Bouncken (Bouncken@uni-bayreuth.de) is a Professor of Strategic Management and Organization at the University of Bayreuth. She received her $\mathrm{Ph} . \mathrm{D}$. at the University of St. Gallen. Her research centers on coopetition, organizational design, and innovation management. Her recent research interest includes the organization of work in collaborative work spaces.

Robin Pesch (robin.pesch@newcastle.ac.uk) is a senior lecturer at Newcastle University Business School. He received his $\mathrm{PhD}$ from the University of Bayreuth. His research focuses on the strategic and organizational design of digitalization and the management of global alliances. 